\title{
Article \\ Mechanical Performance Prediction for Sustainable High-Strength Concrete Using Bio-Inspired Neural Network
}

\author{
Junbo Sun ${ }^{1}$, Jiaqing Wang ${ }^{2}{ }^{\circledR}$, Zhaoyue Zhu ${ }^{3}$, Rui He ${ }^{3}$, Cheng Peng ${ }^{3}$, Chao Zhang ${ }^{4}$, Jizhuo Huang ${ }^{5, *}$, \\ Yufei Wang ${ }^{6, *}$ and Xiangyu Wang ${ }^{6, *}$
}

check for

updates

Citation: Sun, J.; Wang, J.; Zhu, Z.; He, R.; Peng, C.; Zhang, C.; Huang, J.; Wang, Y.; Wang, X. Mechanical Performance Prediction for Sustainable High-Strength Concrete Using Bio-Inspired Neural Network. Buildings 2022, 12, 65. https:// doi.org/10.3390/buildings12010065

Academic Editor: Elena Ferretti

Received: 30 November 2021

Accepted: 5 January 2022

Published: 10 January 2022

Publisher's Note: MDPI stays neutral with regard to jurisdictional claims in published maps and institutional affiliations.

Copyright: (c) 2022 by the authors Licensee MDPI, Basel, Switzerland. This article is an open access article distributed under the terms and conditions of the Creative Commons Attribution (CC BY) license (https:// creativecommons.org/licenses/by/ $4.0 /)$
1 Institute for Smart City of Chongqing University, Chongqing University, Liyang 213300, China; tunneltc@gmail.com

2 College of Civil Engineering, Nanjing Forestry University, Nanjing 210037, China; jiaqingw@njfu.edu.cn

3 School of Architectural Engineering, Nanjing Institute of Technology, Nanjing 211167, China; zhuzhaoyue02002@163.com (Z.Z.); herui756@163.com (R.H.); pengcheng913@163.com (C.P.)

4 Hunan Provincial Key Laboratory of Geotechnical Engineering for Stability Control and Health Monitoring, Hunan University of Science and Technology, Xiangtan 411201, China; flyheartzc@hnust.edu.cn

5 College of Civil Engineering, Fuzhou University, 2 Xue Yuan Rd., University Town, Fuzhou 350116, China

6 School of Design and Built Environment, Curtin University, Perth 6102, Australia

* Correspondence: jzhuang@fzu.edu.cn (J.H.); wangyf0113_suz@163.com (Y.W.); Xiangyu.Wang@curtin.edu.au (X.W.)

\begin{abstract}
High-strength concrete (HSC) is a functional material possessing superior mechanical performance and considerable durability, which has been widely used in long-span bridges and high-rise buildings. Unconfined compressive strength (UCS) is one of the most crucial parameters for evaluating HSC performance. Previously, the mix design of HSC is based on the laboratory test results which is time and money consuming. Nowadays, the UCS can be predicted based on the existing database to guide the mix design with the development of machine learning (ML) such as back-propagation neural network (BPNN). However, the BPNN's hyperparameters (the number of hidden layers, the number of neurons in each layer), which is commonly adjusted by the traditional trial and error method, usually influence the prediction accuracy. Therefore, in this study, BPNN is utilised to predict the UCS of HSC with the hyperparameters tuned by a bio-inspired beetle antennae search (BAS) algorithm. The database is established based on the results of 324 HSC samples from previous literature. The established BAS-BPNN model possesses excellent prediction reliability and accuracy as shown in the high correlation coefficient $(R=0.9893)$ and low Root-meansquare error $(\mathrm{RMSE}=1.5158 \mathrm{MPa})$. By introducing the BAS algorithm, the prediction process can be totally automatical since the optimal hyperparameters of BPNN are obtained automatically. The established BPNN model has the benefit of being applied in practice to support the HSC mix design. In addition, sensitivity analysis is conducted to investigate the significance of input variables. Cement content is proved to influence the UCS most significantly while superplasticizer content has the least significance. However, owing to the dataset limitation and limited performance of ML models which affect the UCS prediction accuracy, further data collection and model update must be implemented.
\end{abstract}

Keywords: high-strength concrete; unconfined compressive strength; beetle antennae search; backpropagation neural network; sensitivity analysis

\section{Introduction}

High-strength concrete (HSC) is a type of cementitious material that has uniaxial compressive strength (UCS) larger than $40 \mathrm{MPa}$ [1-3]. The HSC composite exhibit outstanding mechanical strength, considerable durability, low permeability, and compact density. In addition, it satisfies special uniformity and performance requirements, which is superior to ordinary fabricated concrete [4-6]. HSC has been widely applied in long-span bridges because it sustains superior dead and live loading with fewer bridge piers and thus 
prolongs the service lifespan [7-9]. Meanwhile, HSC is also promising in high buildings because it enables oversized columns to yield more floor space and larger column spacing without detracting from lower floors [10-12]. The behaviour of connectors when embedded in the HSC, such as the shear resistance and ductility, has been investigated by several researchers $[13,14]$. The general behaviour of HSC beams was investigated based on the mid span deflection, failure mode, and crack growth [15]. HSC can also be served as the main construction material accompanied by several advanced technologies, such as building information modelling, 3D printing technology, etc. [16-23]. Besides, solid waste materials, such as waste glass and recycled aggregate, have the potential to be applied in HSC to overcome the strength shortcomings of the waste itself [24-31]. Therefore, HSC incorporated with solid wastes has the benefits of both strength enhancement and sustainable prospect [32-34].

For HSC composites, the uniaxial compressive strength (UCS) is the most significant factor in the design procedure before application. Numerous experiments of HSC by the research facilities have been carried out to investigate the relationship between UCS and its composite constituents. However, the progress is costly and lengthy because too many trial batches have to be prepared to explore desirable mechanical performance with a large number of influencing variables. The pre-configuration of equipment also consumes time and resources. Some conventional evaluation strategies have been used to predict the UCS of HSC composites, such as non-linear regression and linear regression. However, it is still challenging to conduct accurate prediction by applying simple regression models and advanced techniques are in great demand $[35,36]$.

To overcome the above difficulties, machine learning (ML) algorithms have been developed rapidly for predicting the USC of concrete materials. ML models make predictions and decisions by building a mathematical model without being explicit programming based on sample data [37-39]. Many ML models have been used to predict concrete strength, such as neural networks, support vector regression (SVR), and tree-based models [40-43]. For instance, Huynh et al., (2020) [44] utilised artificial neural network (ANN), deep neural network (DNN), and deep residual network (ResNet) to predict the compressive strength of fly ash-based geopolymer concrete. Besides, the deep neural network (DNN) has been applied to perform structural reliability analysis and structural damage detection of truss structures [45,46]. The Extreme Learning Machine (ELM) and ANN were applied and compared to predict the compressive strength of concrete containing fly ash and silica fume [47]. The estimations of moment and rotation in steel rack connections and beam-to-column connections were implemented through ELM [48,49]. Mohammadhassani et al., (2014) [50] used an Adaptive Neuro-Fuzzy Inference System (ANFIS) to predict the shear strength of high strength concrete (HSC) beams without stirrups. The ML models can also be used to further propose multi-objective optimisation design [51-53]. Among most ML models, the back-propagation neural network (BPNN) demonstrates superior predicting capacity for solving engineering problems. The main reason is that BPNN is fast and easy to program without parameters to tune apart from the number of neurons in the hidden layer [54-56]. Therefore, BPNN is chosen as the prediction ML model in this study.

Generally, the number of hidden layers and the optimal number of neurons in each hidden layer are two parameters which significantly affect the performance of BPNN. To determine the two values, traditional trial and error methods are widely used, which is a waste of effort and time. To overcome the shortcoming, some meta-heuristic algorithms were developed for ML model optimisation. Genetic Algorithm (GA) and Particle Swarm Optimization (PSO) accompanied with ANN were applied for properties prediction $[57,58]$. These meta-heuristic algorithms also have extensive use in other ML models. For instance, Sharafati et al., (2020) $[59,60]$ developed a combination of adaptive neuro-fuzzy inference system (ANFIS) with several meta-heuristic algorithms (e.g., PSO) to predict the shear strength of HSC slender beam and compressive strength of foamed concrete. A SVR-GA was employed to predict the shear strength of reinforced concrete (RC) deep beams [61]. Multivariate Adaptive Regression Splines optimized using Water Cycle Algorithm (MARS-WCA) was 
developed for the prediction of the compressive strength of concrete [62]. The grey wolf optimizer (GWO) was implemented with ELM to predict the compressive strength of concrete with partial replacements for cement [63]. It also successfully predicts the behaviour of channel shear connectors in composite floor systems at different temperatures [64]. A Support Vector Machine (SVM) coupled with Firefly Algorithm (FFA) was performed for the shear capacity estimation of angle shear connectors [65]. The Beetle Antennae Search (BAS) is another feasible meta-heuristic algorithm to tune BPNN architecture with fast convergence, stability in local optimization and uncomplicated implementation [41,66,67]. Therefore, BAS algorithm is chosen to tune the hyperparameters of BPNN. Some robust optimisers are also proposed recently such as adaptive hybrid evolutionary firefly algorithm (AHEFA), hybrid differential evolution and symbiotic organisms search (HDS), and evolutionary symbiotic organisms search algorithm (ESOS) [68-70].

In this study, the focus is on predicting the UCS of HSC using BAS-BPNN and understanding the sensitivity ranking of varying influencing factors upon the strength performance of HSC. Different from the traditional ML models, this study develops a novel ML model comprising BPNN and BAS architectures based on a total of 324 experiment data from the literature. The BAS algorithm possesses fast convergence which is beneficial to analysis on the basis of a large database. This pioneering research supplies a novel method to predict the mechanical strength of HSC for advanced engineering construction and application.

\section{Dataset}

A total of 324 HSC data samples are collected from previous literature [71] (listed in the Appendix A). Type 1 ordinary Portland cement (OPC) is used as binder material. Silica sand is incorporated as fine aggregate (FA) and the gravel with the size less than $20 \mathrm{~mm}$ is served as coarse gravel aggregate (CA). A polycarboxylate-based superplasticizer (SP) with a density of $1.06 \mathrm{~g} / \mathrm{cm}^{3}$ is also introduced for adjusting the cement fluidity and segregation performance.

The specific statistics of the input and output variables are summarised in Table 1 based on the database (Appendix A). All the five influencing variables comprise the content of cement, fine and coarse aggregates, water, and SP. The correlation coefficient distribution is computed, as shown demonstrated in Figure 1. According to the result, the UCS is highly correlated with cement. For input variables, most of the correlations are relatively low (less than 0.5$)$, suggesting that these variables will not produce multicollinearity problems [72-74].

Table 1. Chart of input and output statistics.

\begin{tabular}{cccccc}
\hline ID & Data & Unit & Minimum & Maximum & Mean Value \\
\hline Cement & Input & $\mathrm{kg} / \mathrm{m}^{3}$ & 284 & 600 & 417 \\
Water & Input & $\mathrm{kg} / \mathrm{m}^{3}$ & 160 & 180 & 170 \\
Coarse Aggregate & Input & $\mathrm{kg} / \mathrm{m}^{3}$ & 845 & 989 & 899 \\
Fine Aggregate & Input & $\mathrm{kg} / \mathrm{m}^{3}$ & 552 & 951 & 768 \\
SP & Input & $\mathrm{kg} / \mathrm{m}^{3}$ & 0 & 2 & 0.95 \\
UCS & Output & $\mathrm{MPa}$ & 37.5 & 73.6 & 52 \\
\hline
\end{tabular}




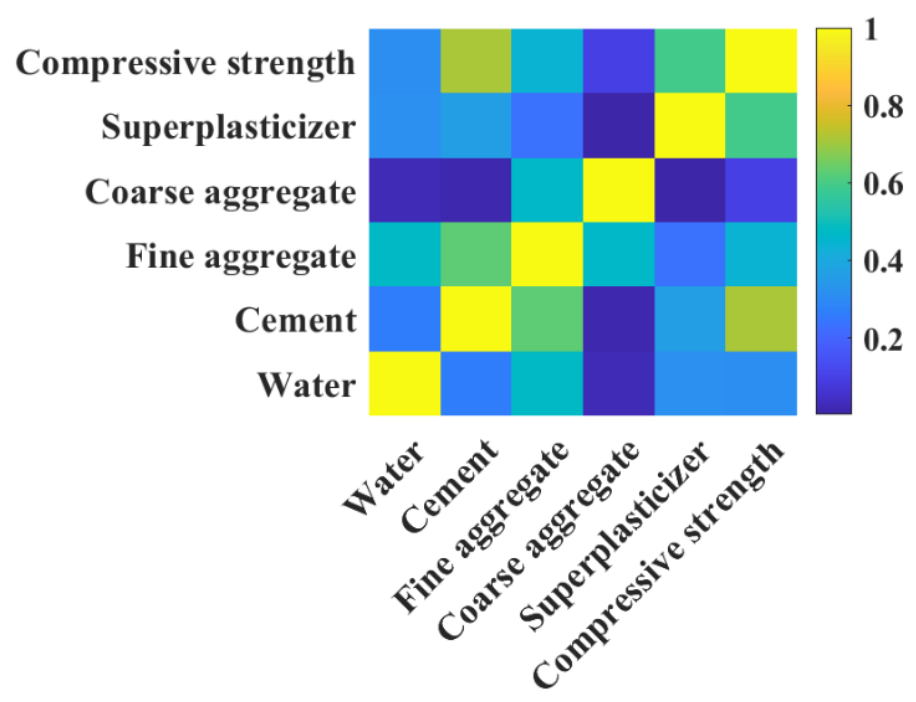

Figure 1. Correlation matrix of the variables of HSC.

\section{Methodology}

\subsection{BPNN}

The artificial neural network (ANN) is one of the commonly used machine learning models, which comprises many categories such as recurrent neural networks (RNN) and feedforward neural network (FFNN). The FFNN includes the Back-propagation neural network (BPNN), which is widely employed to solve problems in the field of building materials and construction $[42,75,76]$. Back propagation (BP) is a popular approach to adjust the weights and bias of the model, which is composed of an input layer, one or more hidden layers, and one output layer. The BP process will compare the actual outputs and predicted outputs to obtain the optimal weight and threshold values of the network. The output $(\mathrm{O})$ of a neuron is computed as follow

$$
\mathrm{O}=\mathrm{f}\left(\sum_{\mathrm{j}=1}^{\mathrm{n}}\left(\mathrm{w}_{\mathrm{j}} \mathrm{x}_{\mathrm{j}}\right)+\mathrm{b}\right), \operatorname{UCS}(\mathrm{MPa})
$$

where $w_{j}$ represents the weight value of the $j$ th input neuron $\left(x_{j}\right)$ in the previous layer; $b$ is the bias value of the output neuron; f denotes the activation function. In this study, the following active function was used mainly due to its superior performance [75]:

$$
f(x)=\frac{2}{1+\exp (-x)}-1
$$

In the backpropagation process, the method computes the gradient of the error function with respect to the weights of the neural networks. The training iteration will stop when the mean square error (MSE) between the actual and predicted outputs become smaller than a defined threshold. The topology of the backpropagation process is shown in Figure 2. 


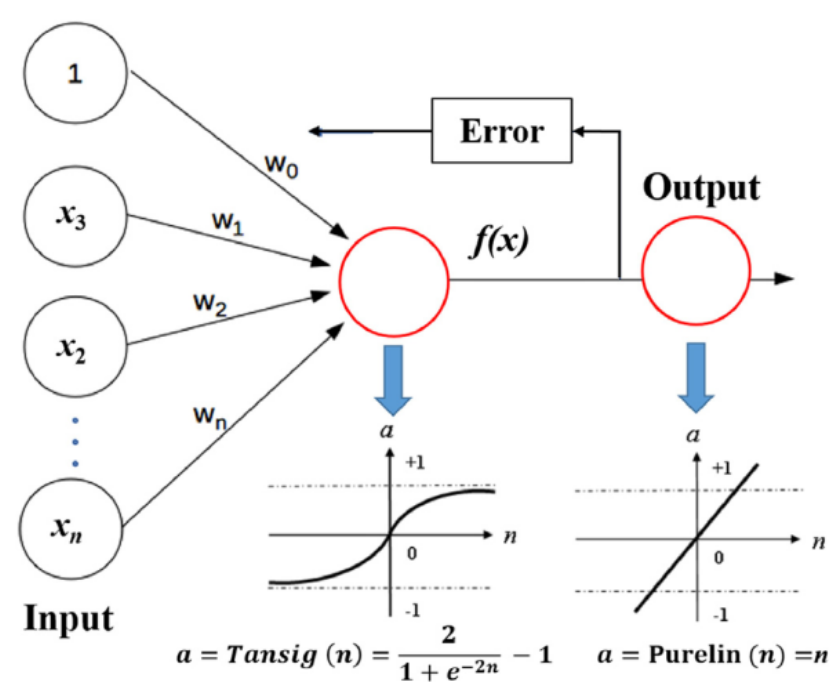

Figure 2. Backpropagation in the BPNN.

\subsection{BAS}

The BAS algorithm is a recently proposed metaheuristic optimization algorithm [77]. It is inspired by the hunting behavior of the longhorn beetle with its two long antennae. The beetle gradually moves to the food source (the global optimum). Therefore, the concentration of odour is represented by the objective function at position $\mathbf{x}$. In a multidimensional space, the global optimum (source point) lies in the position with the best objective value. The beetle's searching behaviour is given by:

$$
\begin{aligned}
& \mathbf{x}_{r}=\mathbf{x}^{i}+d^{i} \mathbf{b} \\
& \mathbf{x}_{l}=\mathbf{x}^{i}-d^{i} \mathbf{b}
\end{aligned}
$$

where $\mathbf{x}_{r}$ and $\mathbf{x}_{l}$ represent the areas in the right-hand side and left-hand side, respectively; $\mathbf{x}^{i}$ is the position at an $i$ th time instant. $d^{i}$ denotes the length of the beetle's antennae at $i$ th iteration. $\mathbf{b}$ denotes a unit vector that is randomly normalized, which is expressed as

$$
\mathrm{b}=\frac{\operatorname{rnd}(\mathrm{k}, 1)}{\|\operatorname{rnd}(\mathrm{k}, 1)\|}
$$

where $\mathrm{k}$ denotes the dimensionality of the position; $\operatorname{rnd}(\cdot)$ is a random function.

The beetle's detecting behaviour is determined using the following equation:

$$
\mathbf{x}^{i+1}=\mathbf{x}^{i}+\delta^{i} \mathbf{b} \cdot \operatorname{sign}\left(f\left(\mathbf{x}_{r}\right)-f\left(\mathbf{x}_{l}\right)\right)
$$

where $\operatorname{sign}(\cdot)$ is the sign function; $\delta^{i}$ represents the step size at the $i$ th iteration, which is updated using the following formula:

$$
\delta^{i+1}=\eta \delta^{i}
$$

where $\eta$ is the attenuation coefficient of the step size.

The flowchart of BAS is shown in Figure 3 and the pseudocode of tuning hyperparameters of BPNN using BAS is presented in Figure 4. 


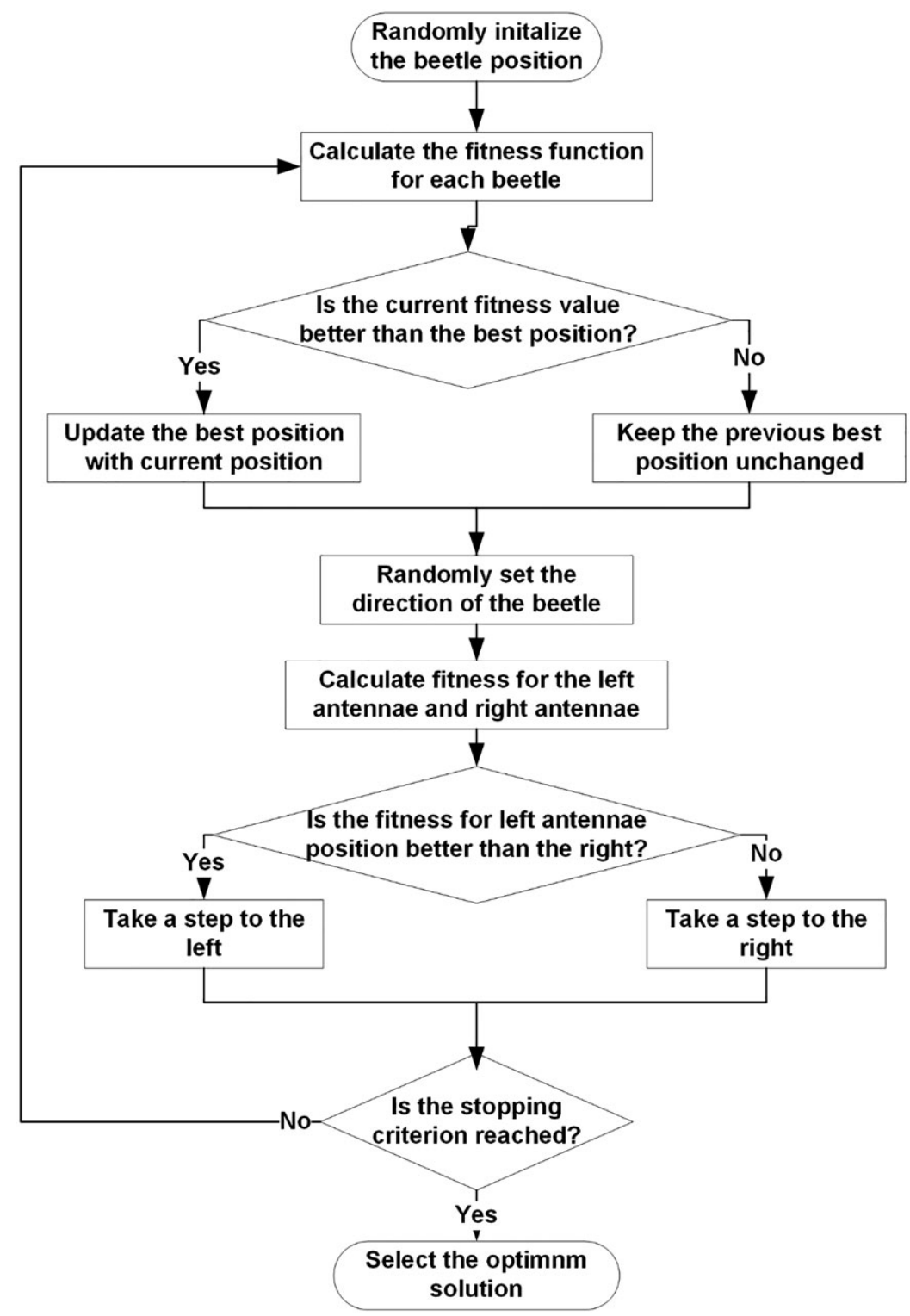

Figure 3. Flowchart of BAS.

Input: Training set $\boldsymbol{D}_{\boldsymbol{t}}$ and validation set $\boldsymbol{D}_{\boldsymbol{v}}$ from dataset $\boldsymbol{D}, \mathrm{BPNN}$ training and testing process BPNN $\left(\boldsymbol{D}, \boldsymbol{x}^{\boldsymbol{i}}\right)$, initial hyperparameter set $\boldsymbol{x}^{\mathbf{0}}$

Output: Optimised hyperparameters $\boldsymbol{x}_{\boldsymbol{b}}$, maximum iteration $\boldsymbol{n}$

For $i=1$ to $n$

Calculate the left and right positions $\boldsymbol{x}_{\boldsymbol{l}}$ and $\boldsymbol{x}_{\boldsymbol{r}}$ of the beetle

Calculate the Root-mean-square error (RMSE) values in $\boldsymbol{D}_{\boldsymbol{v}}$ for implementing BPNN

$\left(\boldsymbol{D}, \boldsymbol{x}_{\boldsymbol{l}}\right)$ and BPNN $\left(\boldsymbol{D}, \boldsymbol{x}_{\boldsymbol{r}}\right)$ with hyperparameters $\boldsymbol{x}_{\boldsymbol{l}}$ and $\boldsymbol{x}_{\boldsymbol{r}}$, respectively

Calculate the next position $x^{i+1}$

Calculate the RMSE in $\boldsymbol{D}_{v}$ in process $\operatorname{BPNN}\left(\boldsymbol{D}, \boldsymbol{x}^{\boldsymbol{i + 1}}\right)$ with hyperparameter $\boldsymbol{x}^{\boldsymbol{i + 1}}$

Update $\boldsymbol{x}_{\boldsymbol{b}}$

$i=i+1$

End

Figure 4. The pseudocode of tuning hyperparameters of BPNN using BAS, reprinted from ref. [78]. 


\subsection{Performance Evaluation}

In this study, Root-mean-square error (RMSE) and Correlation coefficient (R) are used to evaluate the performance of the proposed model. RMSE and R are calculated as follows

$$
\text { RMSE }=\sqrt{\frac{1}{n} \sum_{i=1}^{n}\left(y_{i}^{*}-y_{i}\right)^{2}}, \mathrm{MPa}
$$

where $n$ denotes the number of data samples; $y_{i}^{*}$ is the predicted value; $y_{i}$ represents the actual value;

$$
R=\frac{\sum_{i=1}^{n}\left(y_{i}^{*}-\overline{y^{*}}\right)\left(y_{i}-\bar{y}\right)}{\sqrt{\sum_{i=1}^{n}\left(y_{i}^{*}-\overline{y^{*}}\right)^{2}} \sqrt{\sum_{i=1}^{n}\left(y_{i}-\bar{y}\right)^{2}}} \text { dimensionless }
$$

where and are the mean value of predicted and observed values, respectively.

\subsection{Determination of Architecture of BPNN}

The hidden layer and the number of neurons in each hidden layer are optimised using BAS in this study. To tune these hyperparameters, 10-fold cross validation (CV) was performed in the training set (Figure 5). The training set is divided into 10 folds, in which 9 folds are used to tune the number of neurons by BAS, and the performance of the BPNN model with the optimal architecture is validated in the remaining fold. After repeating 10 times (for each time, a different fold is selected as the validation fold), the average neuron number is selected as the final neuron number used in this study. Finally, $30 \%$ of the data in the test set are used to test the performance of the BPNN with optimal architecture.

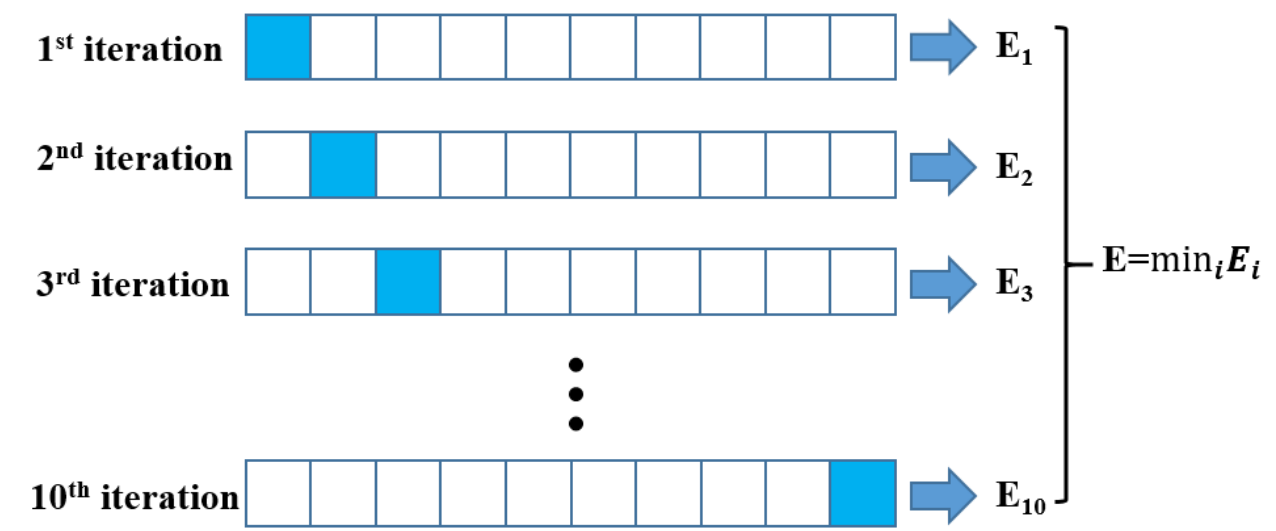

Figure 5. 10-fold cross validation.

\section{Results and Discussion}

\subsection{Results of Hyperparameter Tuning}

In this study, the number of neurons in each layer is tuned using the BAS algorithm. In each fold, the RMSE obtained by the BPNN (with optimal neuron number of this fold) is plotted in Figure 6. The smallest RMSE values versus iterations corresponding to varying hidden layers are shown in Figure 7, which presents the process of neuron number tuning. It can be seen that the RMSE decreases to its minimum value within 40 iterations, suggesting that BAS has high efficiency in finding the optimal number of neurons. Ultimately, the final hidden layer is 1 and the corresponding optimal neuron number is 24 . 


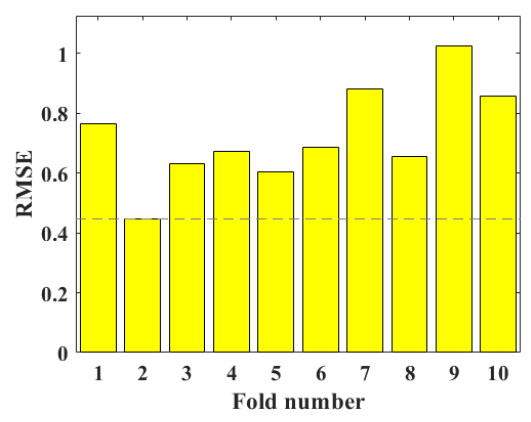

(a)

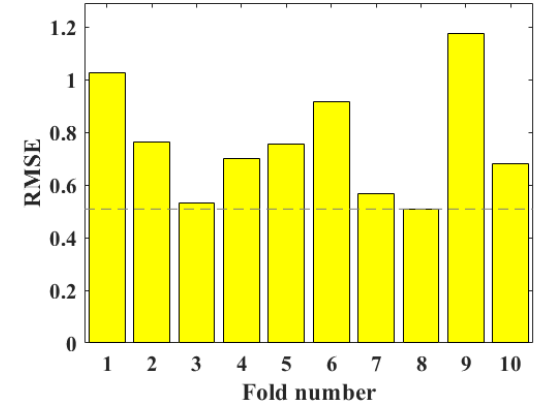

(b)

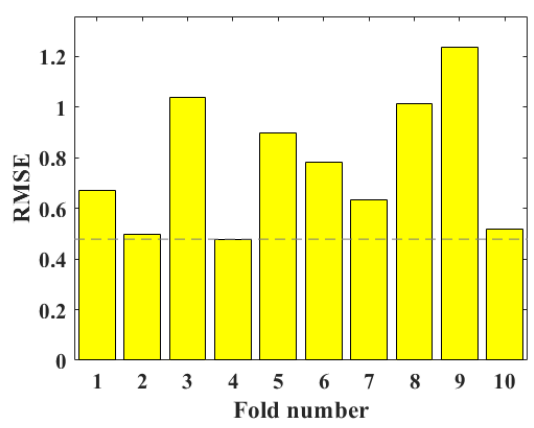

(c)

Figure 6. RMSE value in each fold when hidden layer is 1 (a), 2 (b), and 3 (c).

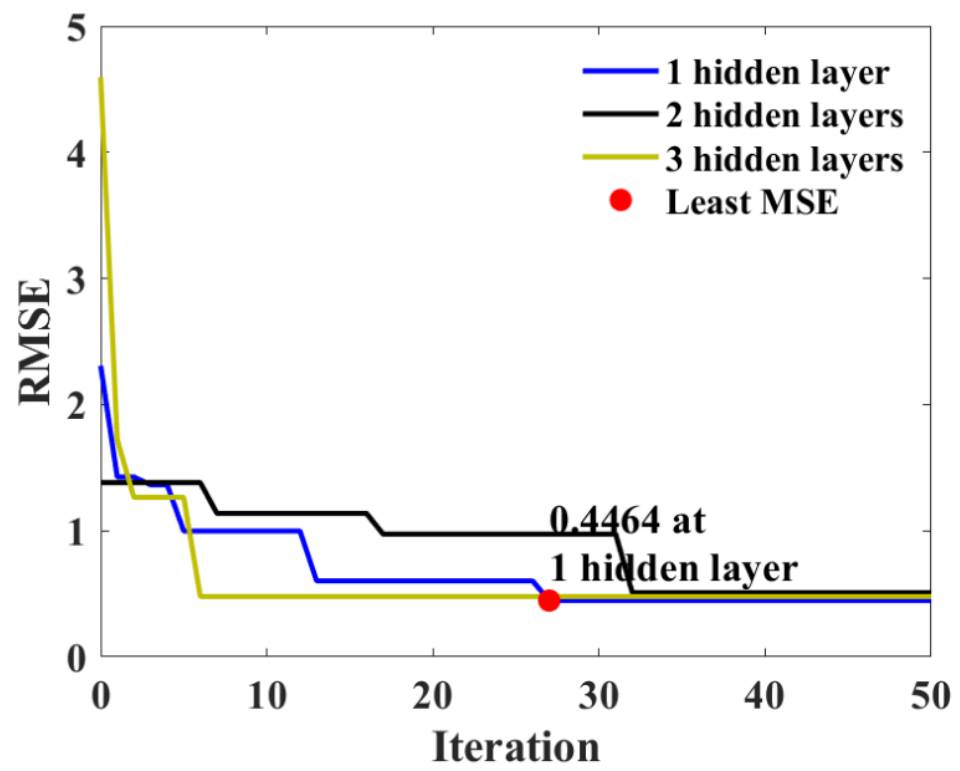

Figure 7. The lowest RMSE versus iteration corresponding to different hidden layers.

\subsection{Performance of the BAS-BPNN Model}

Figure 8 shows the actual values (blue line), predicted values (red point), and errors between the actual and predicted UCS (yellow bar graph). It can be observed that although several large noises are observed, most of the errors are pretty small on the training set (Figure 8a) and test set (Figure 8b). This result indicates that the BAS-BPNN model is highly accurate. The correlation between the actual and predicted UCS is visualized in Figure 9. High prediction accuracy is observed on the training set (Figure 9a) and test set (Figure $9 b$ ), as indicated by the high $\mathrm{R}$ values ( 0.9971 and 0.9893 on the training and test sets, respectively) and low RMSE values (0.7167 MPa and $1.5158 \mathrm{MPa}$ on the training and test sets, respectively). Compared with previously published papers [42,51], the obtained results show much higher accuracy ( $R$ is around 0.99 ), which might be attributed to the model performance or the accuracy and size of the database. Furthermore, no overfitting problems take place as the test set RMSE (and R) is close to that on the training set. Owing to the inherent stochastic properties of the BAS algorithm, the statistical outcomes of extra 20 run times are also reported in Table 2 to verify the robustness of the introduced ML model. 


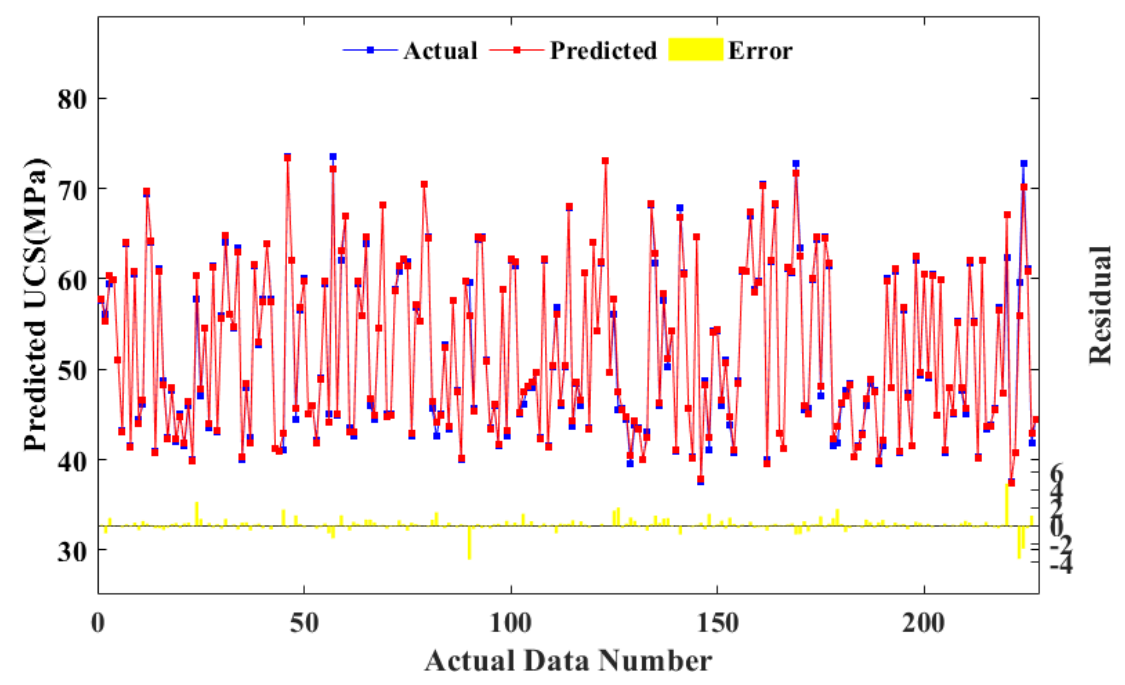

(a)

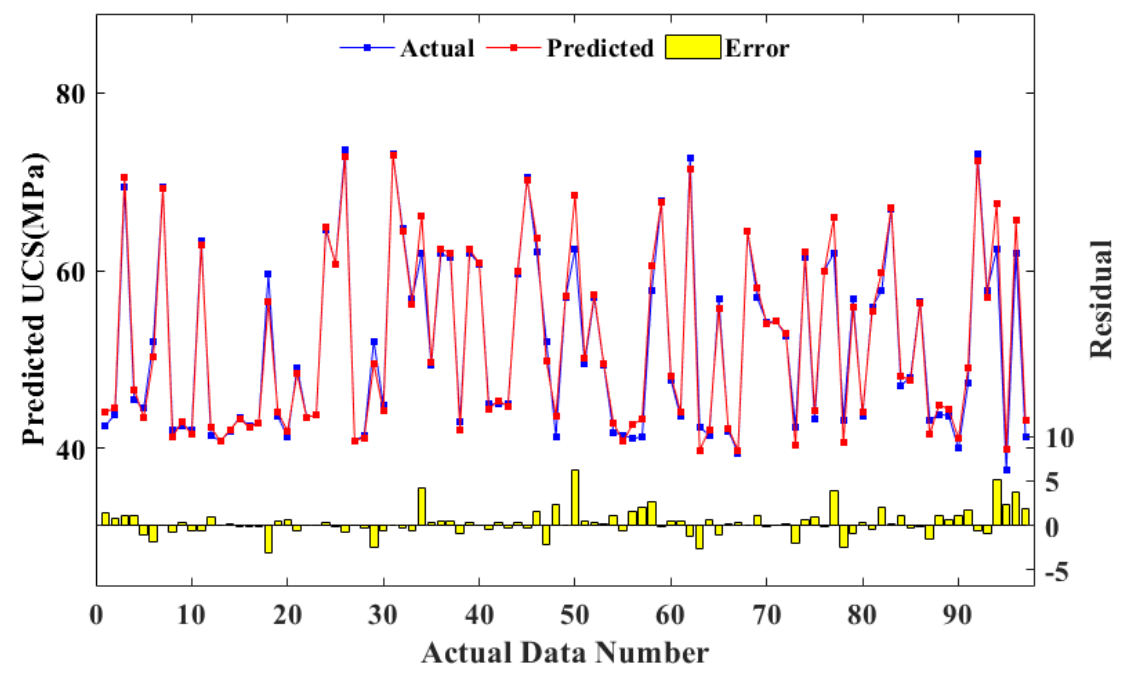

(b)

Figure 8. The error between actual and predicted UCS values on the training set (a) and test set (b).

Table 2. Statistical outcomes (RMSE, R) of the BAS-BPNN for the extra 20 run times.

\begin{tabular}{cccccc}
\hline Run Time & $\begin{array}{c}\text { RMSE of Training } \\
\text { and Test Sets } \\
\mathbf{( M P a )}\end{array}$ & $\begin{array}{c}\text { R of Training and } \\
\text { Test Sets }\end{array}$ & $\begin{array}{c}\text { Run Time } \\
\text { RMSE of Training } \\
\text { and Test Sets } \\
\mathbf{( M P a )}\end{array}$ & $\begin{array}{c}\text { R of Training and } \\
\text { Test Sets }\end{array}$ \\
\hline 1 & $1.0036,1.1543$ & $0.9945,0.9922$ & 11 & $1.3392,1.1305$ & $0.9893,0.9942$ \\
2 & $1.0879,1.3876$ & $0.9933,0.9894$ & 12 & $0.9725,1.0086$ & $0.9949,0.9937$ \\
3 & $0.8851,1.2874$ & $0.9956,0.9906$ & 13 & $1.1523,1.1125$ & $0.9929,0.9919$ \\
4 & $1.0482,1.0455$ & $0.9935,0.9945$ & 14 & $1.1654,1.3617$ & $0.9925,0.9898$ \\
5 & $1.3044,1.6762$ & $0.9914,0.9844$ & 15 & $0.9353,1.0637$ & $0.9951,0.9940$ \\
6 & $0.8887,1.1730$ & $0.9955,0.9927$ & 16 & $1.1210,1.3923$ & $0.9929,0.9891$ \\
7 & $1.0657,1.2421$ & $0.9940,0.9919$ & 17 & $1.1539,1.3263$ & $0.9928,0.9896$ \\
8 & $0.9304,1.8270$ & $0.9953,0.9804$ & 18 & $1.2006,1.2839$ & $0.9925,0.9901$ \\
9 & $0.9678,1.3371$ & $0.9948,0.9898$ & 19 & $0.9878,1.2744$ & $0.9945,0.9913$ \\
10 & $1.2053,1.5601$ & $0.9921,0.9875$ & 20 & $0.8121,1.1521$ & $0.9960,0.9945$ \\
\hline
\end{tabular}




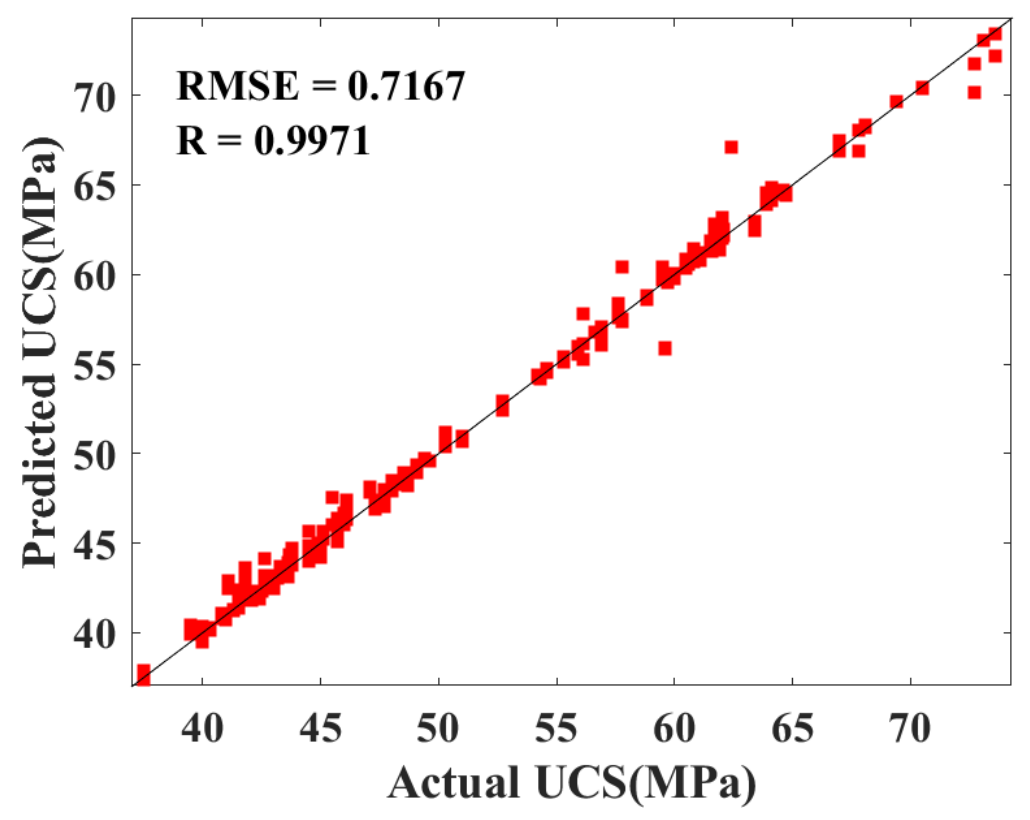

(a)

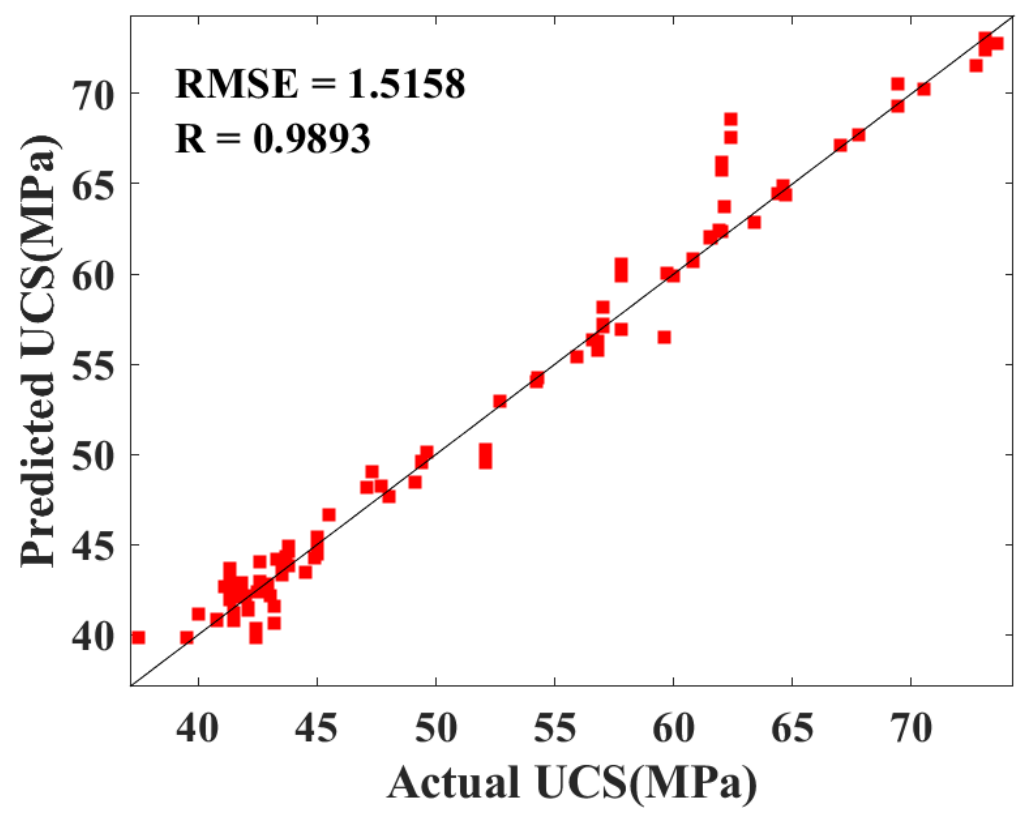

(b)

Figure 9. Predicted UCS versus actual UCS on the training set (a) and test set (b).

\subsection{Variable Importance}

Global sensitivity analysis (GSA) is combined with the developed BPNN model to analyse the variable importance (Figure 10). It can measure the impact on the proposed BAS-BPNN output when the input value changes within its value range [79]. The data sample is represented as $\mathrm{x}$, and $\mathrm{x}_{a}, a \in\{1, \ldots, M\}$ denotes an input variable through its range with $L$ levels ( $M$ is the number of input variables). And $y$ represents the UCS value which is predicted by the BPNN. According to the range of $x_{a}$ and $L$ levels, the input variable $\mathrm{x}_{a}$ can be divided into $i$ values, namely, $\mathrm{x}_{a i}, i=\{1, \ldots, L\}$. The respective 
sensitivity response of each input variable is calculated by Equation (10). Afterward, the relative importance of each variable is calculated by Equation (11).

$$
\begin{gathered}
g_{a}=\sum_{i=2}^{L} \frac{\left|y_{a, i}-y_{a, \hat{i}-1}\right|}{L-1} \\
R_{a}=g_{a} / \sum_{i=1}^{L} g_{i}
\end{gathered}
$$

where $a$ is the input variable that needs to be analysed; $\hat{y_{a}, i}, i=\{1, \ldots, L\}$ stands for the sensitivity response indicator for $\mathrm{x}_{a i}, i=\{1, \ldots, L\} ; R_{a}$ is the relative importance of the variable.

It can be observed that UCS of HSC is the most sensitive to contents of cement and water with importance ratios of $44.9 \%$ and $34.9 \%$, respectively. This is mainly due to the water-to-cement ratio, which is crucial to the development of concrete strength. It is interesting to note that superplasticiser (importance ratio $=2.7 \%$ ) is not as important as other influencing variables. This may be caused by insufficient content of superplasticiser in the concrete mixtures. It is worthwhile to note that the importance of input variables is calculated on the basis of the data set collected in this study, as listed in the Appendix A.

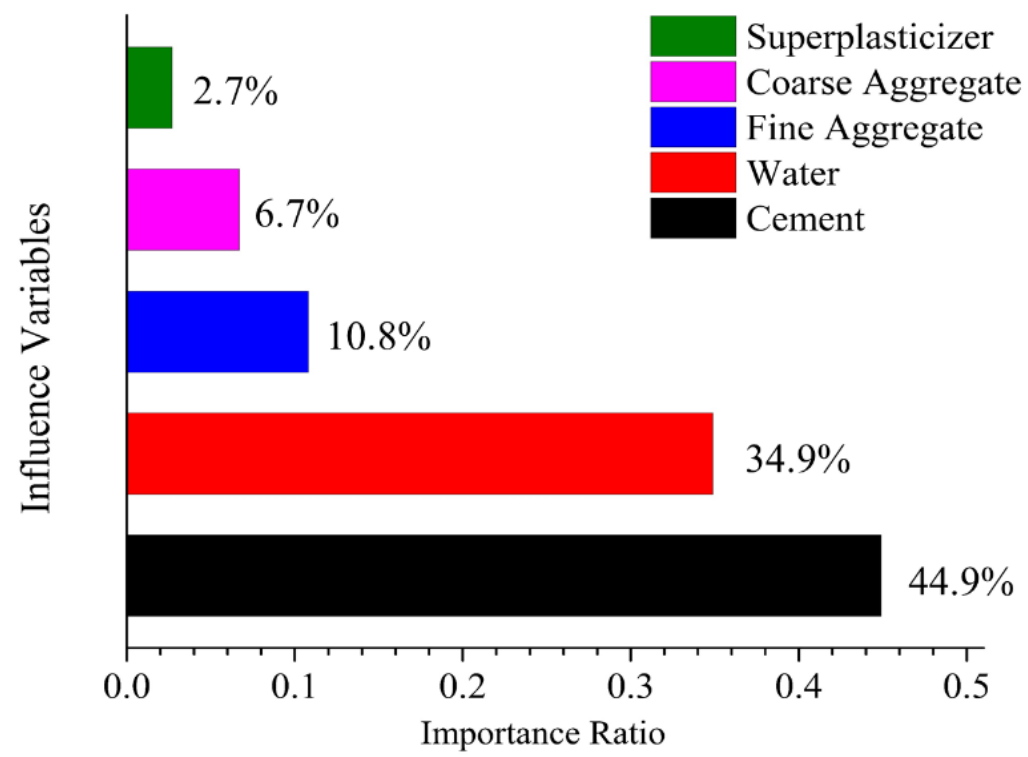

Figure 10. Variable importance of the input variables.

\subsection{Comparison of the BAS-BPNN Model with Other ML Models}

To seek the optimal ML model and further verify the strength of the established BASBPNN model in the prediction of UCS of HSC, its prediction performance is compared with several widely used ML models [80]: Support vector machine (SVM), random forest (RF), K-nearest neighbours (KNN), logistic regression (LR), and multiple-linear regression (MLR). Among these models, the hyperparameters of SVM, RF, and KNN are also tuned by BAS. The tuned hyperparameters with their empirical scopes, initial values, and final values are listed in Table 3. The hyperparameter tuning process of these models is shown in Figure 11. It can be seen that all RMSE curves can converge within 50 iterations, indicating the high searching efficiency of the BAS algorithm. In the first 20 iterations, the RMSE obtained by SVM decreases less significantly in comparison with that obtained by other ML models. This implies the initial hyperparameters of SVM are close to the optimal hyperparameters. 
Table 3. Hyperparameters of different models.

\begin{tabular}{|c|c|c|c|c|}
\hline Classifier & Hyperparameter & Empirical Scope & Initial Value & Final Value \\
\hline \multirow{2}{*}{ SVM } & Coefficient of the penalty term & {$[1,1000]$} & 16 & 18.73 \\
\hline & Gamma value of gaussian kernel & {$[0.1,10]$} & 16 & 34.88 \\
\hline \multirow{2}{*}{ RF } & $\begin{array}{l}\text { The minimum number of samples } \\
\text { required to split an internal node }\end{array}$ & {$[1,10]$} & 40 & 1 \\
\hline & The total number of trees & {$[2,100]$} & 40 & 83 \\
\hline KNN & Number of neighbor samples & {$[1,10]$} & 30 & 2 \\
\hline
\end{tabular}

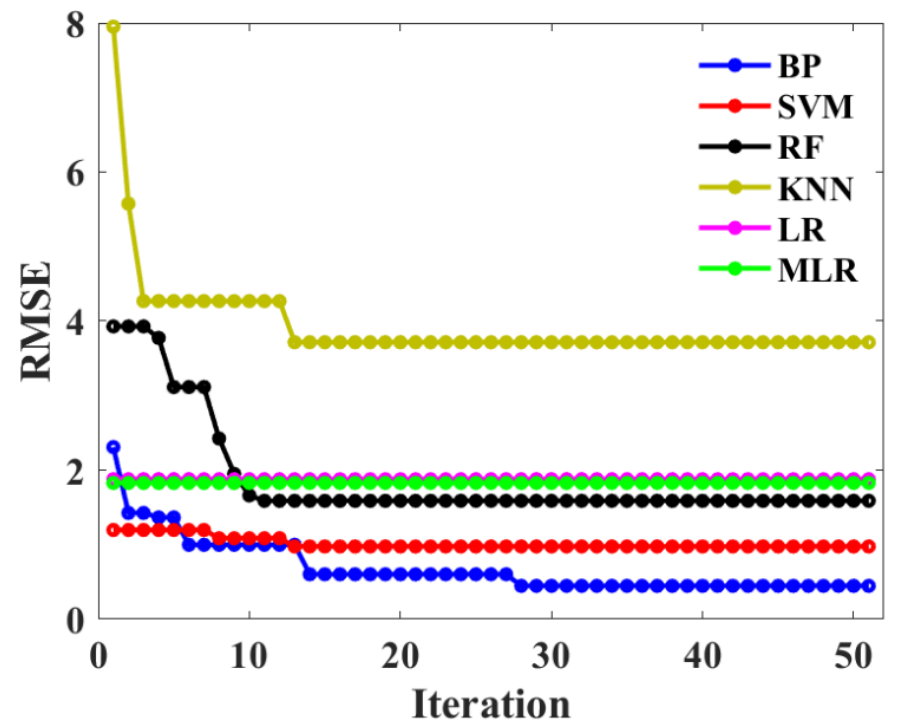

Figure 11. Hyperparameter tuning by different models on the training set.

The prediction errors of different ML models are compared on the test set using a boxplot, as shown in Figure 12. The lower edge of the box represents the first quartile, and the upper edge is the third quartile. The median is demonstrated as a red line in the box. The lower and upper whiskers are the 1.5 IQR minus the first quartile and 1.5 IQR above the third quartile, respectively (IQR is the interquartile range). All the other data points are defined as outliers in this study. It can be observed that BPNN has the smallest third quartile, indicating that most of the errors obtained by BPNN are relatively small. Although few outliers were observed in BPNN, the general prediction performance was the best among these ML models. The advantage of BAS-BPNN is also verified by comparing different ML models using a Taylor plot that shows in Figure 13, indicating three model evaluation indices (standard deviation, RMSE, and R). The ML model will be the most realistic if the distance between the ML model and the point labelled "Actual" is the shortest. It can be seen that BPNN is the closest to the "Actual point", suggesting BPNN performs better in terms of standard deviation, correlation coefficient, and RMSE. Generally, the boxplot and Taylor plot present a similar phenomenon, ranking the accuracy of ML models as BP, SVM, RF, MLR, LR, and KNN. This is controlled according to the model complexity and database suitability. According to the "no free lunch" (NFL) theorem of machine learning, there is no single model that performs universally superior to other models for any dataset. Therefore, based on the dataset used in this study, BPNN is the optimal prediction model. 


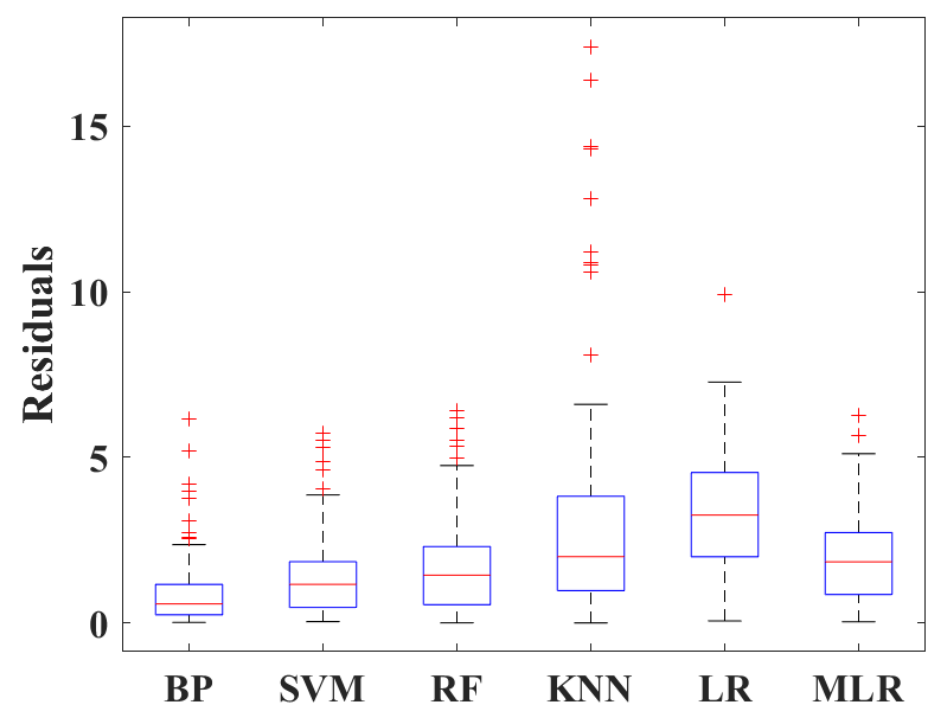

Figure 12. Boxplot showing the errors between predicted and actual UCS values on the test sets for different models.

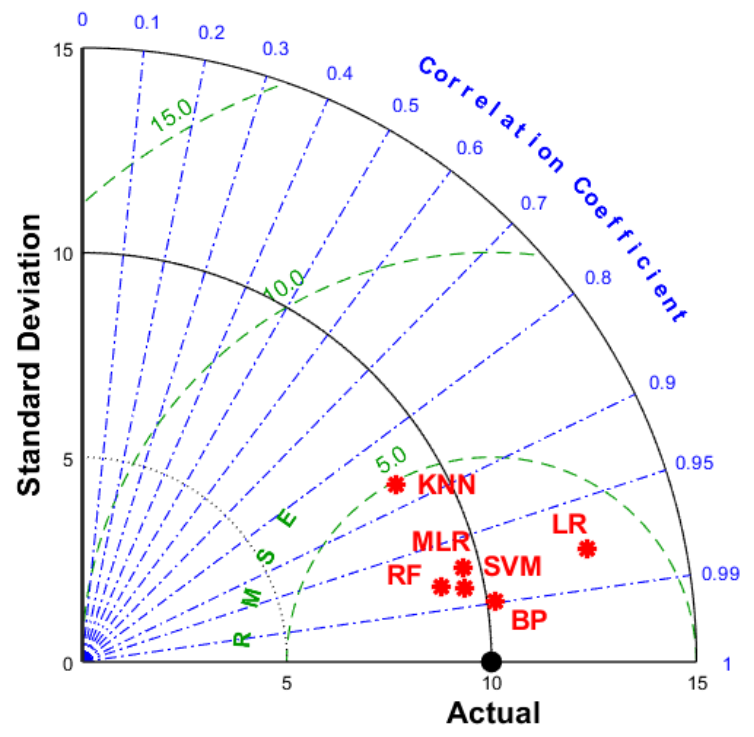

Figure 13. Taylor plot showing the errors between predicted and actual UCS values on the test sets for different models.

\section{Conclusions}

In this study, the BPNN model with the BAS algorithm being used to tune the hyperparameters was established to predict the UCS of HSC. The proposed BAS-BPNN model was developed based on a collected dataset containing over 300 HSC samples with different mixtures. The BPNNs with 1, 2, and 3 hidden layers were compared and the ultimate optimal architecture is one hidden layer with 24 neurons. The results show that BAS has high efficiency in tuning hyperparameters of BPNN and the obtained BAS-BPNN model is highly accurate $(\mathrm{R}=0.9893$, RMSE $=1.5158 \mathrm{MPa}$ on the test set). Besides, the BAS-BPNN is superior by comparing its prediction performance with other widely used ML models (SVM, RF, KNN, LR, and MLR). In addition, the importance ranking of the input variables through GSA was implemented showing that cement and water are the most significant variables to the UCS of HSC. Generally, the findings in this study can be used in practice to support the HSC mix design.

It is noted that only five input variables are considered in this study, which inevitably influences the diversity and size of the database. Therefore, more samples containing 
varying raw materials such as fly ash, slags, and other solid wastes will be incorporated in the future to further improve the generalisation ability of the BAS-BPNN model. Also, other active functions, advanced machine learning models, and optimization algorithms (e.g., AHEFA, HDS, and ESOS) can be applied for performance comparison. An Adaptive Neuro-Fuzzy Inference System can be used to determine the most influencing parameters to further verify the findings in this study $[81,82]$.

Author Contributions: Conceptualization, J.S.; methodology, J.S.; software, Y.W.; validation, Z.Z.; formal analysis, J.W.; investigation, R.H.; resources, C.P.; data curation, C.Z.; writing-original draft preparation, J.H.; writing—review and editing, Y.W.; visualization, Y.W.; supervision, X.W.; project administration, J.S.; funding acquisition, X.W. All authors have read and agreed to the published version of the manuscript.

Funding: This research is funded by the Academic Research Council of Australia Linkage Projects for Asset Intelligence: Maximising Operational Effectiveness for Digital Era, (Grant No. LP180100222); It is also supported by State Key Laboratory for GeoMechanics and Deep Underground Engineering, China University of Mining \& Technology/China University of Mining \& Technology, Beijing) (SKLGDUEK2105).

Data Availability Statement: The data presented in this study are openly available.

Conflicts of Interest: The authors declare no conflict of interest.

\section{Appendix A}

\begin{tabular}{|c|c|c|c|c|c|c|}
\hline ID & $\begin{array}{c}\text { Water } \\
\left(\mathrm{kg} / \mathrm{m}^{3}\right)\end{array}$ & $\begin{array}{c}\mathrm{OPC} \\
\left(\mathrm{kg} / \mathrm{m}^{3}\right)\end{array}$ & $\underset{\left(\mathrm{kg} / \mathrm{m}^{3}\right)}{\text { FA }}$ & $\underset{\left(\mathrm{kg} / \mathrm{m}^{3}\right)}{\mathrm{CA}}$ & $\begin{array}{c}\mathrm{SP} \\
\left(\mathrm{kg} / \mathrm{m}^{3}\right)\end{array}$ & $\begin{array}{c}\text { UCS } \\
\text { (MPa) }\end{array}$ \\
\hline 1 & 160 & 533 & 805 & 845 & 1 & 73.6 \\
\hline 2 & 160 & 533 & 805 & 845 & 1.5 & 73.6 \\
\hline 3 & 160 & 533 & 805 & 845 & 2 & 73.6 \\
\hline 4 & 160 & 480 & 786 & 845 & 1 & 73.1 \\
\hline 5 & 160 & 480 & 786 & 845 & 1.5 & 73.1 \\
\hline 6 & 160 & 480 & 786 & 845 & 2 & 73.1 \\
\hline 7 & 160 & 427 & 767 & 845 & 1 & 72.7 \\
\hline 8 & 160 & 427 & 767 & 845 & 1.5 & 72.7 \\
\hline 9 & 160 & 427 & 767 & 845 & 2 & 72.7 \\
\hline 10 & 160 & 533 & 753 & 898 & 1 & 69.4 \\
\hline 11 & 160 & 533 & 753 & 898 & 1.5 & 69.4 \\
\hline 12 & 160 & 533 & 753 & 898 & 2 & 69.4 \\
\hline 13 & 160 & 480 & 734 & 898 & 1 & 70.5 \\
\hline 14 & 160 & 480 & 734 & 898 & 1.5 & 70.5 \\
\hline 15 & 160 & 480 & 734 & 898 & 2 & 70.5 \\
\hline 16 & 160 & 427 & 715 & 898 & 1 & 68.1 \\
\hline 17 & 160 & 427 & 715 & 898 & 1.5 & 68.1 \\
\hline 18 & 160 & 427 & 715 & 898 & 2 & 68.1 \\
\hline 19 & 160 & 533 & 701 & 950 & 1 & 67.8 \\
\hline 20 & 160 & 533 & 701 & 950 & 1.5 & 67.8 \\
\hline 21 & 160 & 533 & 701 & 950 & 2 & 67.8 \\
\hline 22 & 160 & 480 & 682 & 950 & 1 & 67 \\
\hline 23 & 160 & 480 & 682 & 950 & 1.5 & 67 \\
\hline 24 & 160 & 480 & 682 & 950 & 2 & 67 \\
\hline 25 & 160 & 427 & 663 & 950 & 1 & 64.1 \\
\hline 26 & 160 & 427 & 663 & 950 & 1.5 & 64.1 \\
\hline 27 & 160 & 427 & 663 & 950 & 2 & 64.1 \\
\hline 28 & 170 & 567 & 751 & 845 & 1 & 64.6 \\
\hline 29 & 170 & 567 & 751 & 845 & 1.5 & 64.6 \\
\hline 30 & 170 & 567 & 751 & 845 & 2 & 64.6 \\
\hline 31 & 170 & 510 & 731 & 845 & 1 & 64.4 \\
\hline
\end{tabular}




\begin{tabular}{|c|c|c|c|c|c|c|}
\hline ID & $\begin{array}{c}\text { Water } \\
\left(\mathrm{kg} / \mathrm{m}^{3}\right)\end{array}$ & $\begin{array}{c}\mathrm{OPC} \\
\left(\mathrm{kg} / \mathrm{m}^{3}\right)\end{array}$ & $\underset{\left(\mathrm{kg} / \mathrm{m}^{3}\right)}{\text { FA }}$ & $\underset{\left(\mathrm{kg} / \mathrm{m}^{3}\right)}{\mathrm{CA}}$ & $\begin{array}{c}\mathrm{SP} \\
\left(\mathrm{kg} / \mathrm{m}^{3}\right)\end{array}$ & $\begin{array}{c}\text { UCS } \\
\text { (MPa) }\end{array}$ \\
\hline 32 & 170 & 510 & 731 & 845 & 1.5 & 64.4 \\
\hline 33 & 170 & 510 & 731 & 845 & 2 & 64.4 \\
\hline 34 & 170 & 453 & 711 & 845 & 1 & 64.7 \\
\hline 35 & 170 & 453 & 711 & 845 & 1.5 & 64.7 \\
\hline 36 & 170 & 453 & 711 & 845 & 2 & 64.7 \\
\hline 37 & 170 & 567 & 700 & 898 & 1 & 63.9 \\
\hline 38 & 170 & 567 & 700 & 898 & 1.5 & 63.9 \\
\hline 39 & 170 & 567 & 700 & 898 & 2 & 63.9 \\
\hline 40 & 170 & 510 & 679 & 898 & 1 & 63.4 \\
\hline 41 & 170 & 510 & 679 & 898 & 1.5 & 63.4 \\
\hline 42 & 170 & 510 & 679 & 898 & 2 & 63.4 \\
\hline 43 & 170 & 453 & 659 & 898 & 1 & 62 \\
\hline 44 & 170 & 453 & 659 & 898 & 1.5 & 62 \\
\hline 45 & 170 & 453 & 659 & 898 & 2 & 62 \\
\hline 46 & 170 & 567 & 648 & 950 & 1 & 62.4 \\
\hline 47 & 170 & 567 & 648 & 950 & 1.5 & 62.4 \\
\hline 48 & 170 & 567 & 648 & 950 & 2 & 62.4 \\
\hline 49 & 170 & 510 & 628 & 950 & 1 & 61.7 \\
\hline 50 & 170 & 510 & 628 & 950 & 1.5 & 61.7 \\
\hline 51 & 170 & 510 & 628 & 950 & 2 & 61.7 \\
\hline 52 & 170 & 453 & 608 & 950 & 1 & 61.9 \\
\hline 53 & 170 & 453 & 608 & 950 & 1.5 & 61.9 \\
\hline 54 & 170 & 453 & 608 & 950 & 2 & 61.9 \\
\hline 55 & 180 & 600 & 698 & 845 & 0.75 & 59.5 \\
\hline 56 & 180 & 600 & 698 & 845 & 1.25 & 59.5 \\
\hline 57 & 180 & 600 & 698 & 845 & 1.75 & 59.5 \\
\hline 58 & 180 & 540 & 677 & 845 & 0.75 & 61.1 \\
\hline 59 & 180 & 540 & 677 & 845 & 1.25 & 61.1 \\
\hline 60 & 180 & 540 & 677 & 845 & 1.75 & 61.1 \\
\hline 61 & 180 & 480 & 655 & 845 & 0.75 & 60.8 \\
\hline 62 & 180 & 480 & 655 & 845 & 1.25 & 60.8 \\
\hline 63 & 180 & 480 & 655 & 845 & 1.75 & 60.8 \\
\hline 64 & 180 & 600 & 646 & 898 & 0.75 & 60.5 \\
\hline 65 & 180 & 600 & 646 & 898 & 1.25 & 60.5 \\
\hline 66 & 180 & 600 & 646 & 898 & 1.75 & 60.5 \\
\hline 67 & 180 & 540 & 625 & 898 & 0.75 & 59.9 \\
\hline 68 & 180 & 540 & 625 & 898 & 1.25 & 59.9 \\
\hline 69 & 180 & 540 & 625 & 898 & 1.75 & 59.9 \\
\hline 70 & 180 & 480 & 604 & 898 & 0.75 & 57 \\
\hline 71 & 180 & 480 & 604 & 898 & 1.25 & 57 \\
\hline 72 & 180 & 480 & 604 & 898 & 1.75 & 57 \\
\hline 73 & 180 & 600 & 594 & 950 & 0.75 & 59.7 \\
\hline 74 & 180 & 600 & 594 & 950 & 1.25 & 59.7 \\
\hline 75 & 180 & 600 & 594 & 950 & 1.75 & 59.7 \\
\hline 76 & 180 & 540 & 573 & 950 & 0.75 & 60 \\
\hline 77 & 180 & 540 & 573 & 950 & 1.25 & 60 \\
\hline 78 & 180 & 540 & 573 & 950 & 1.75 & 60 \\
\hline 79 & 180 & 480 & 552 & 950 & 0.75 & 59.6 \\
\hline 80 & 180 & 480 & 552 & 950 & 1.25 & 59.6 \\
\hline 81 & 180 & 480 & 552 & 950 & 1.75 & 59.6 \\
\hline 82 & 160 & 457 & 867 & 845 & 0.75 & 62 \\
\hline 83 & 160 & 457 & 867 & 845 & 1.25 & 62 \\
\hline 84 & 160 & 457 & 867 & 845 & 1.75 & 62 \\
\hline 85 & 160 & 411 & 851 & 845 & 0.75 & 62 \\
\hline 86 & 160 & 411 & 851 & 845 & 1.25 & 62 \\
\hline 87 & 160 & 411 & 851 & 845 & 1.75 & 62 \\
\hline
\end{tabular}




\begin{tabular}{|c|c|c|c|c|c|c|}
\hline ID & $\begin{array}{c}\text { Water } \\
\left(\mathrm{kg} / \mathrm{m}^{3}\right)\end{array}$ & $\begin{array}{c}\text { OPC } \\
\left(\mathrm{kg} / \mathrm{m}^{3}\right)\end{array}$ & $\underset{\left(\mathrm{kg} / \mathrm{m}^{3}\right)}{\text { FA }}$ & $\underset{\left(\mathrm{kg} / \mathrm{m}^{3}\right)}{\mathrm{CA}}$ & $\begin{array}{c}\mathrm{SP} \\
\left(\mathrm{kg} / \mathrm{m}^{3}\right)\end{array}$ & $\begin{array}{c}\text { UCS } \\
(\mathrm{MPa})\end{array}$ \\
\hline 88 & 160 & 366 & 835 & 845 & 0.75 & 60.6 \\
\hline 89 & 160 & 366 & 835 & 845 & 1.25 & 60.6 \\
\hline 90 & 160 & 366 & 835 & 845 & 1.75 & 60.6 \\
\hline 91 & 160 & 457 & 816 & 898 & 0.75 & 62.1 \\
\hline 92 & 160 & 457 & 816 & 898 & 1.25 & 62.1 \\
\hline 93 & 160 & 457 & 816 & 898 & 1.75 & 62.1 \\
\hline 94 & 160 & 411 & 799 & 898 & 0.75 & 61.5 \\
\hline 95 & 160 & 411 & 799 & 898 & 1.25 & 61.5 \\
\hline 96 & 160 & 411 & 799 & 898 & 1.75 & 61.5 \\
\hline 97 & 160 & 366 & 783 & 898 & 0.75 & 57.8 \\
\hline 98 & 160 & 366 & 783 & 898 & 1.25 & 57.8 \\
\hline 99 & 160 & 366 & 783 & 898 & 1.75 & 57.8 \\
\hline 100 & 160 & 457 & 764 & 950 & 0.75 & 61.5 \\
\hline 101 & 160 & 457 & 764 & 950 & 1.25 & 61.5 \\
\hline 102 & 160 & 457 & 764 & 950 & 1.75 & 61.5 \\
\hline 103 & 160 & 411 & 747 & 950 & 0.75 & 60.8 \\
\hline 104 & 160 & 411 & 747 & 950 & 1.25 & 60.8 \\
\hline 105 & 160 & 411 & 747 & 950 & 1.75 & 60.8 \\
\hline 106 & 160 & 366 & 731 & 950 & 0.75 & 57.6 \\
\hline 107 & 160 & 366 & 731 & 950 & 1.25 & 57.6 \\
\hline 108 & 160 & 366 & 731 & 950 & 1.75 & 57.6 \\
\hline 109 & 170 & 486 & 818 & 845 & 0.5 & 58.8 \\
\hline 110 & 170 & 486 & 818 & 845 & 1 & 58.8 \\
\hline 111 & 170 & 486 & 818 & 845 & 1.5 & 58.8 \\
\hline 112 & 170 & 437 & 801 & 845 & 0.5 & 56.8 \\
\hline 113 & 170 & 437 & 801 & 845 & 1 & 56.8 \\
\hline 114 & 170 & 437 & 801 & 845 & 1.5 & 56.8 \\
\hline 115 & 170 & 389 & 783 & 845 & 0.5 & 55.3 \\
\hline 116 & 170 & 389 & 783 & 845 & 1 & 55.3 \\
\hline 117 & 170 & 389 & 783 & 845 & 1.5 & 55.3 \\
\hline 118 & 170 & 486 & 766 & 898 & 0.5 & 57.8 \\
\hline 119 & 170 & 486 & 766 & 898 & 1 & 57.8 \\
\hline 120 & 170 & 486 & 766 & 898 & 1.5 & 57.8 \\
\hline 121 & 170 & 437 & 749 & 898 & 0.5 & 56.6 \\
\hline 122 & 170 & 437 & 749 & 898 & 1 & 56.6 \\
\hline 123 & 170 & 437 & 749 & 898 & 1.5 & 56.6 \\
\hline 124 & 170 & 389 & 732 & 898 & 0.5 & 56.9 \\
\hline 125 & 170 & 389 & 732 & 898 & 1 & 56.9 \\
\hline 126 & 170 & 389 & 732 & 898 & 1.5 & 56.9 \\
\hline 127 & 170 & 486 & 714 & 950 & 0.5 & 56.1 \\
\hline 128 & 170 & 486 & 714 & 950 & 1 & 56.1 \\
\hline 129 & 170 & 486 & 714 & 950 & 1.5 & 56.1 \\
\hline 130 & 170 & 437 & 697 & 950 & 0.5 & 55.9 \\
\hline 131 & 170 & 437 & 697 & 950 & 1 & 55.9 \\
\hline 132 & 170 & 437 & 697 & 950 & 1.5 & 55.9 \\
\hline 133 & 170 & 389 & 680 & 950 & 0.5 & 54.3 \\
\hline 134 & 170 & 389 & 680 & 950 & 1 & 54.3 \\
\hline 135 & 170 & 389 & 680 & 950 & 1.5 & 54.3 \\
\hline 136 & 180 & 514 & 769 & 845 & 0.25 & 54.2 \\
\hline 137 & 180 & 514 & 769 & 845 & 0.75 & 54.2 \\
\hline 138 & 180 & 514 & 769 & 845 & 1.25 & 54.2 \\
\hline 139 & 180 & 463 & 750 & 845 & 0.25 & 52.7 \\
\hline 140 & 180 & 463 & 750 & 845 & 0.75 & 52.7 \\
\hline 141 & 180 & 463 & 750 & 845 & 1.25 & 52.7 \\
\hline 142 & 180 & 411 & 732 & 845 & 0.25 & 51 \\
\hline 143 & 180 & 411 & 732 & 845 & 0.75 & 51 \\
\hline 144 & 180 & 411 & 732 & 845 & 1.25 & 51 \\
\hline 145 & 180 & 514 & 717 & 898 & 0.25 & 54.6 \\
\hline 146 & 180 & 514 & 717 & 898 & 0.75 & 54.6 \\
\hline
\end{tabular}




\begin{tabular}{|c|c|c|c|c|c|c|}
\hline ID & $\begin{array}{c}\text { Water } \\
\left(\mathrm{kg} / \mathrm{m}^{3}\right)\end{array}$ & $\begin{array}{c}\text { OPC } \\
\left(\mathrm{kg} / \mathrm{m}^{3}\right)\end{array}$ & $\begin{array}{c}\text { FA } \\
\left(\mathrm{kg} / \mathrm{m}^{3}\right)\end{array}$ & $\begin{array}{c}\mathrm{CA} \\
\left(\mathrm{kg} / \mathrm{m}^{3}\right)\end{array}$ & $\begin{array}{c}\mathrm{SP} \\
\left(\mathrm{kg} / \mathrm{m}^{3}\right)\end{array}$ & $\begin{array}{c}\text { UCS } \\
(\mathrm{MPa})\end{array}$ \\
\hline 147 & 180 & 514 & 717 & 898 & 1.25 & 54.6 \\
\hline 148 & 180 & 463 & 698 & 898 & 0.25 & 50.3 \\
\hline 149 & 180 & 463 & 698 & 898 & 0.75 & 50.3 \\
\hline 150 & 180 & 463 & 698 & 898 & 1.25 & 50.3 \\
\hline 151 & 180 & 411 & 680 & 898 & 0.25 & 47.3 \\
\hline 152 & 180 & 411 & 680 & 898 & 0.75 & 47.3 \\
\hline 153 & 180 & 411 & 680 & 898 & 1.25 & 47.3 \\
\hline 154 & 180 & 514 & 665 & 950 & 0.25 & 52.1 \\
\hline 155 & 180 & 514 & 665 & 950 & 0.75 & 52.1 \\
\hline 156 & 180 & 514 & 665 & 950 & 1.25 & 52.1 \\
\hline 157 & 180 & 463 & 647 & 950 & 0.5 & 45.5 \\
\hline 158 & 180 & 463 & 647 & 950 & 1 & 45.5 \\
\hline 159 & 180 & 463 & 647 & 950 & 1.5 & 45.5 \\
\hline 160 & 180 & 411 & 628 & 950 & 0.5 & 45.7 \\
\hline 161 & 180 & 411 & 628 & 950 & 1 & 45.7 \\
\hline 162 & 180 & 411 & 628 & 950 & 1.5 & 45.7 \\
\hline 163 & 160 & 400 & 914 & 845 & 0.5 & 49.6 \\
\hline 164 & 160 & 400 & 914 & 845 & 1 & 49.6 \\
\hline 165 & 160 & 400 & 914 & 845 & 1.5 & 49.6 \\
\hline 166 & 160 & 360 & 900 & 845 & 0.5 & 48 \\
\hline 167 & 160 & 360 & 900 & 845 & 1 & 48 \\
\hline 168 & 160 & 360 & 900 & 845 & 1.5 & 48 \\
\hline 169 & 160 & 320 & 886 & 845 & 0.5 & 47.7 \\
\hline 170 & 160 & 320 & 886 & 845 & 1 & 47.7 \\
\hline 171 & 160 & 320 & 886 & 845 & 1.5 & 47.7 \\
\hline 172 & 160 & 400 & 863 & 989 & 0.5 & 49.1 \\
\hline 173 & 160 & 400 & 863 & 989 & 1 & 49.1 \\
\hline 174 & 160 & 400 & 863 & 989 & 1.5 & 49.1 \\
\hline 175 & 160 & 360 & 848 & 898 & 0.5 & 48 \\
\hline 176 & 160 & 360 & 848 & 898 & 1 & 48 \\
\hline 177 & 160 & 360 & 848 & 898 & 1.5 & 48 \\
\hline 178 & 160 & 320 & 834 & 898 & 0.5 & 48.5 \\
\hline 179 & 160 & 320 & 834 & 898 & 1 & 48.5 \\
\hline 180 & 160 & 320 & 834 & 898 & 1.5 & 48.5 \\
\hline 181 & 160 & 400 & 811 & 950 & 0.5 & 49.4 \\
\hline 182 & 160 & 400 & 811 & 950 & 1 & 49.4 \\
\hline 183 & 160 & 400 & 811 & 950 & 1.5 & 49.4 \\
\hline 184 & 160 & 360 & 797 & 950 & 0.5 & 48.7 \\
\hline 185 & 160 & 360 & 797 & 950 & 1 & 48.7 \\
\hline 186 & 160 & 360 & 797 & 950 & 1.5 & 48.7 \\
\hline 187 & 160 & 320 & 782 & 950 & 0.5 & 46.1 \\
\hline 188 & 160 & 320 & 782 & 950 & 1 & 46.1 \\
\hline 189 & 160 & 320 & 782 & 950 & 1.5 & 46.1 \\
\hline 190 & 170 & 425 & 868 & 845 & 0 & 47.7 \\
\hline 191 & 170 & 425 & 868 & 845 & 0.5 & 47.7 \\
\hline 192 & 170 & 425 & 868 & 845 & 1 & 47.7 \\
\hline 193 & 170 & 425 & 853 & 845 & 0 & 47.1 \\
\hline 194 & 170 & 425 & 853 & 845 & 0.5 & 47.1 \\
\hline 195 & 170 & 425 & 853 & 845 & 1 & 47.1 \\
\hline 196 & 170 & 340 & 838 & 845 & 0 & 45 \\
\hline 197 & 170 & 340 & 838 & 845 & 0.5 & 45 \\
\hline 198 & 170 & 340 & 838 & 845 & 1 & 45 \\
\hline 199 & 170 & 425 & 816 & 898 & 0 & 46 \\
\hline 200 & 170 & 425 & 816 & 898 & 0.5 & 46 \\
\hline 201 & 170 & 425 & 816 & 898 & 1 & 46 \\
\hline 202 & 170 & 383 & 801 & 898 & 0 & 45.7 \\
\hline 203 & 170 & 383 & 801 & 898 & 0.5 & 45.7 \\
\hline 204 & 170 & 383 & 801 & 898 & 1 & 45.7 \\
\hline 205 & 170 & 340 & 786 & 898 & 0 & 45.1 \\
\hline
\end{tabular}




\begin{tabular}{|c|c|c|c|c|c|c|}
\hline ID & $\begin{array}{c}\text { Water } \\
\left(\mathrm{kg} / \mathrm{m}^{3}\right)\end{array}$ & $\begin{array}{c}\text { OPC } \\
\left(\mathrm{kg} / \mathrm{m}^{3}\right)\end{array}$ & $\underset{\left(\mathrm{kg} / \mathrm{m}^{3}\right)}{\text { FA }}$ & $\underset{\left(\mathrm{kg} / \mathrm{m}^{3}\right)}{\mathrm{CA}}$ & $\begin{array}{c}\mathrm{SP} \\
\left(\mathrm{kg} / \mathrm{m}^{3}\right)\end{array}$ & $\begin{array}{c}\text { UCS } \\
(\mathrm{MPa})\end{array}$ \\
\hline 206 & 170 & 340 & 786 & 898 & 0.5 & 45.1 \\
\hline 207 & 170 & 340 & 786 & 898 & 1 & 45.1 \\
\hline 208 & 170 & 425 & 764 & 950 & 0 & 46 \\
\hline 209 & 170 & 425 & 764 & 950 & 0.5 & 46 \\
\hline 210 & 170 & 425 & 764 & 950 & 1 & 46 \\
\hline 211 & 170 & 383 & 749 & 950 & 0 & 45 \\
\hline 212 & 170 & 383 & 749 & 950 & 0.5 & 45 \\
\hline 213 & 170 & 383 & 749 & 950 & 1 & 45 \\
\hline 214 & 170 & 340 & 734 & 950 & 0 & 43.3 \\
\hline 215 & 170 & 340 & 734 & 950 & 0.5 & 43.3 \\
\hline 216 & 170 & 340 & 734 & 950 & 1 & 43.3 \\
\hline 217 & 180 & 450 & 821 & 845 & 0 & 44.5 \\
\hline 218 & 180 & 450 & 821 & 845 & 0.5 & 44.5 \\
\hline 219 & 180 & 450 & 821 & 845 & 1 & 44.5 \\
\hline 220 & 180 & 405 & 805 & 845 & 0 & 43.6 \\
\hline 221 & 180 & 405 & 805 & 845 & 0.5 & 43.6 \\
\hline 222 & 180 & 405 & 805 & 845 & 1 & 43.6 \\
\hline 223 & 180 & 360 & 789 & 845 & 0 & 42 \\
\hline 224 & 180 & 360 & 789 & 845 & 0.5 & 42 \\
\hline 225 & 180 & 360 & 789 & 845 & 1 & 42 \\
\hline 226 & 180 & 450 & 770 & 898 & 0 & 43.8 \\
\hline 227 & 180 & 450 & 770 & 898 & 0.5 & 43.8 \\
\hline 228 & 180 & 450 & 770 & 898 & 1 & 43.8 \\
\hline 229 & 180 & 405 & 754 & 898 & 0 & 43 \\
\hline 230 & 180 & 405 & 754 & 898 & 0.5 & 43 \\
\hline 231 & 180 & 405 & 754 & 898 & 1 & 43 \\
\hline 232 & 180 & 360 & 738 & 898 & 0 & 43.2 \\
\hline 233 & 180 & 360 & 738 & 898 & 0.5 & 43.2 \\
\hline 234 & 180 & 360 & 738 & 898 & 1 & 43.2 \\
\hline 235 & 180 & 450 & 718 & 950 & 0 & 43.5 \\
\hline 236 & 180 & 450 & 718 & 950 & 0.5 & 43.5 \\
\hline 237 & 180 & 450 & 718 & 950 & 1 & 43.5 \\
\hline 238 & 180 & 405 & 702 & 950 & 0 & 41.5 \\
\hline 239 & 180 & 405 & 702 & 950 & 0.5 & 41.5 \\
\hline 240 & 180 & 405 & 702 & 950 & 1 & 41.5 \\
\hline 241 & 180 & 360 & 686 & 950 & 0 & 42.4 \\
\hline 242 & 180 & 360 & 686 & 950 & 0.5 & 42.4 \\
\hline 243 & 180 & 360 & 686 & 950 & 1 & 42.4 \\
\hline 244 & 160 & 356 & 951 & 845 & 0.5 & 46 \\
\hline 245 & 160 & 356 & 951 & 845 & 1 & 46 \\
\hline 246 & 160 & 356 & 951 & 845 & 1.5 & 46 \\
\hline 247 & 160 & 320 & 938 & 845 & 0.5 & 45 \\
\hline 248 & 160 & 320 & 938 & 845 & 1 & 45 \\
\hline 249 & 160 & 320 & 938 & 845 & 1.5 & 45 \\
\hline 250 & 160 & 284 & 926 & 845 & 0.5 & 43.7 \\
\hline 251 & 160 & 284 & 926 & 845 & 1 & 43.7 \\
\hline 252 & 160 & 284 & 926 & 845 & 1.5 & 43.7 \\
\hline 253 & 160 & 356 & 899 & 898 & 0.5 & 44.5 \\
\hline 254 & 160 & 356 & 899 & 898 & 1 & 44.5 \\
\hline 255 & 160 & 356 & 899 & 898 & 1.5 & 44.5 \\
\hline 256 & 160 & 320 & 886 & 898 & 0.5 & 42.6 \\
\hline 257 & 160 & 320 & 886 & 898 & 1 & 42.6 \\
\hline 258 & 160 & 320 & 886 & 898 & 1.5 & 42.6 \\
\hline 259 & 160 & 284 & 874 & 898 & 0.5 & 43.8 \\
\hline 260 & 160 & 284 & 874 & 898 & 1 & 43.8 \\
\hline 261 & 160 & 284 & 874 & 898 & 1.5 & 43.8 \\
\hline 262 & 160 & 356 & 847 & 950 & 0.5 & 43.6 \\
\hline 263 & 160 & 356 & 847 & 950 & 1 & 43.6 \\
\hline
\end{tabular}




\begin{tabular}{|c|c|c|c|c|c|c|}
\hline ID & $\begin{array}{c}\text { Water } \\
\left(\mathrm{kg} / \mathrm{m}^{3}\right)\end{array}$ & $\begin{array}{c}\text { OPC } \\
\left(\mathrm{kg} / \mathrm{m}^{3}\right)\end{array}$ & $\underset{\left(\mathrm{kg} / \mathrm{m}^{3}\right)}{\text { FA }}$ & $\underset{\left(\mathrm{kg} / \mathrm{m}^{3}\right)}{\mathrm{CA}}$ & $\begin{array}{c}\mathrm{SP} \\
\left(\mathrm{kg} / \mathrm{m}^{3}\right)\end{array}$ & $\begin{array}{c}\text { UCS } \\
(\mathrm{MPa})\end{array}$ \\
\hline 264 & 160 & 356 & 847 & 950 & 1.5 & 43.6 \\
\hline 265 & 160 & 320 & 835 & 950 & 0.5 & 42.6 \\
\hline 266 & 160 & 320 & 835 & 950 & 1 & 42.6 \\
\hline 267 & 160 & 320 & 835 & 950 & 1.5 & 42.6 \\
\hline 268 & 160 & 284 & 822 & 950 & 0.5 & 42.9 \\
\hline 269 & 160 & 284 & 822 & 950 & 1 & 42.9 \\
\hline 270 & 160 & 284 & 822 & 950 & 1.5 & 42.9 \\
\hline 271 & 170 & 378 & 907 & 845 & 0.5 & 44.9 \\
\hline 272 & 170 & 378 & 907 & 845 & 1 & 44.9 \\
\hline 273 & 170 & 378 & 907 & 845 & 1.5 & 44.9 \\
\hline 274 & 170 & 340 & 893 & 845 & 0 & 41.1 \\
\hline 275 & 170 & 340 & 893 & 845 & 0.5 & 41.1 \\
\hline 276 & 170 & 340 & 893 & 845 & 1 & 41.1 \\
\hline 277 & 170 & 302 & 880 & 845 & 0 & 41.5 \\
\hline 278 & 170 & 302 & 880 & 845 & 0.5 & 41.5 \\
\hline 279 & 170 & 302 & 880 & 845 & 1 & 41.5 \\
\hline 280 & 170 & 378 & 855 & 898 & 0 & 42.5 \\
\hline 281 & 170 & 378 & 855 & 898 & 0.5 & 42.5 \\
\hline 282 & 170 & 378 & 855 & 898 & 1 & 42.5 \\
\hline 283 & 170 & 340 & 842 & 898 & 0 & 40.8 \\
\hline 284 & 170 & 340 & 842 & 898 & 0.5 & 40.8 \\
\hline 285 & 170 & 340 & 842 & 898 & 1 & 40.8 \\
\hline 286 & 170 & 302 & 828 & 898 & 0 & 40.8 \\
\hline 287 & 170 & 302 & 828 & 898 & 0.5 & 40.8 \\
\hline 288 & 170 & 302 & 828 & 898 & 1 & 40.8 \\
\hline 289 & 170 & 378 & 803 & 950 & 0 & 41.8 \\
\hline 290 & 170 & 378 & 803 & 950 & 0.5 & 41.8 \\
\hline 291 & 170 & 378 & 803 & 950 & 1 & 41.8 \\
\hline 292 & 170 & 340 & 790 & 950 & 0 & 41.3 \\
\hline 293 & 170 & 340 & 790 & 950 & 0.5 & 41.3 \\
\hline 294 & 170 & 340 & 790 & 950 & 1 & 41.3 \\
\hline 295 & 170 & 302 & 776 & 950 & 0 & 41 \\
\hline 296 & 170 & 302 & 776 & 950 & 0.5 & 41 \\
\hline 297 & 170 & 302 & 776 & 950 & 1 & 41 \\
\hline 298 & 180 & 400 & 863 & 845 & 0 & 41.3 \\
\hline 299 & 180 & 400 & 863 & 845 & 0.5 & 41.3 \\
\hline 300 & 180 & 400 & 863 & 845 & 1 & 41.3 \\
\hline 301 & 180 & 360 & 848 & 845 & 0 & 41.5 \\
\hline 302 & 180 & 360 & 848 & 845 & 0.5 & 41.5 \\
\hline 303 & 180 & 360 & 848 & 845 & 1 & 41.5 \\
\hline 304 & 180 & 320 & 834 & 845 & 0 & 40.3 \\
\hline 305 & 180 & 320 & 834 & 845 & 0.5 & 40.3 \\
\hline 306 & 180 & 320 & 834 & 845 & 1 & 40.3 \\
\hline 307 & 180 & 400 & 811 & 898 & 0 & 41.5 \\
\hline 308 & 180 & 400 & 811 & 898 & 0.5 & 41.5 \\
\hline 309 & 180 & 400 & 811 & 898 & 1 & 41.5 \\
\hline 310 & 180 & 360 & 797 & 898 & 0 & 40 \\
\hline 311 & 180 & 360 & 797 & 898 & 0.5 & 40 \\
\hline 312 & 180 & 360 & 797 & 898 & 1 & 40 \\
\hline 313 & 180 & 320 & 782 & 898 & 0 & 40 \\
\hline 314 & 180 & 320 & 782 & 898 & 0.5 & 40 \\
\hline 315 & 180 & 320 & 782 & 898 & 1 & 40 \\
\hline 316 & 180 & 400 & 759 & 950 & 0 & 42.1 \\
\hline 317 & 180 & 400 & 759 & 950 & 0.5 & 42.1 \\
\hline 318 & 180 & 400 & 759 & 950 & 1 & 42.1 \\
\hline
\end{tabular}




\begin{tabular}{|c|c|c|c|c|c|c|}
\hline ID & $\begin{array}{c}\text { Water } \\
\left(\mathrm{kg} / \mathrm{m}^{3}\right)\end{array}$ & $\begin{array}{c}\text { OPC } \\
\left(\mathrm{kg} / \mathrm{m}^{3}\right)\end{array}$ & $\underset{\left(\mathrm{kg} / \mathrm{m}^{3}\right)}{\text { FA }}$ & $\underset{\left(\mathrm{kg} / \mathrm{m}^{3}\right)}{\mathrm{CA}}$ & $\begin{array}{c}\mathrm{SP} \\
\left(\mathrm{kg} / \mathrm{m}^{3}\right)\end{array}$ & $\begin{array}{c}\text { UCS } \\
\text { (MPa) }\end{array}$ \\
\hline 319 & 180 & 360 & 745 & 950 & 0 & 39.5 \\
\hline 320 & 180 & 360 & 745 & 950 & 0.5 & 39.5 \\
\hline 321 & 180 & 360 & 745 & 950 & 1 & 39.5 \\
\hline 322 & 180 & 320 & 731 & 950 & 0 & 37.5 \\
\hline 323 & 180 & 320 & 731 & 950 & 0.5 & 37.5 \\
\hline 324 & 180 & 320 & 731 & 950 & 1 & 37.5 \\
\hline
\end{tabular}

\section{References}

1. Carrasquillo, R.L.; Nilson, A.H.; Slate, F.O. Properties of High Strength Concrete Subjectto Short-Term Loads. J. Proc. 1981, 78, 171-178.

2. Zhang, W.; Tang, Z.; Yang, Y.; Wei, J.; Stanislav, P. Mixed-Mode Debonding Behavior between CFRP Plates and Concrete under Fatigue Loading. J. Struct. Eng. 2021, 147, 04021055. [CrossRef]

3. Dehghani, A.; Hayatdavoodi, A.; Aslani, F. The ultimate shear capacity of longitudinally stiffened steel-concrete composite plate girders. J. Constr. Steel Res. 2021, 179, 106550. [CrossRef]

4. Mbessa, M.; Péra, J. Durability of high-strength concrete in ammonium sulfate solution. Cem. Concr. Res. 2001, 31, 1227-1231. [CrossRef]

5. Zhang, W.; Tang, Z. Numerical Modeling of Response of CFRP-Concrete Interfaces Subjected to Fatigue Loading. J. Compos. Constr. 2021, 25, 04021043. [CrossRef]

6. Hayatdavoodi, A.; Dehghani, A.; Aslani, F.; Nateghi-Alahi, F. The development of a novel analytical model to design composite steel plate shear walls under eccentric shear. J. Build. Eng. 2021, 44, 103281. [CrossRef]

7. Wang, Q.; Wang, D.; Chen, H. The role of fly ash microsphere in the microstructure and macroscopic properties of high-strength concrete. Cem. Concr. Compos. 2017, 83, 125-137. [CrossRef]

8. Xu, S.; Wang, J.; Shou, W.; Ngo, T.; Sadick, A.-M.; Wang, X. Computer vision techniques in construction: A critical review. Arch . Comput. Methods Eng. 2021, 28, 3383-3397. [CrossRef]

9. Dehghani, A.; Mozafari, A.R.; Aslani, F. Evaluation of the efficacy of using engineered cementitious composites in RC beamcolumn joints. Structures 2020, 27, 151-162. [CrossRef]

10. Saradar, A.; Tahmouresi, B.; Mohseni, E.; Shadmani, A. Restrained shrinkage cracking of fiber-reinforced high-strength concrete. Fibers 2018, 6, 12. [CrossRef]

11. Aslani, F.; Deghani, A.; Gunawardena, Y. Experimental investigation of the behavior of concrete-filled high-strength glass fiber-reinforced polymer tubes under static and cyclic axial compression. Struct. Concr. 2020, 21, 1497-1522. [CrossRef]

12. Dehghani, A.; Aslani, F. Fatigue performance and design of concrete-filled steel tubular joints: A critical review. J. Constr. Steel Res. 2019, 162, 105749. [CrossRef]

13. Shariati, M.; Sulong, N.R.; Kueh, A. Comparative performance of channel and angle shear connectors in high strength concrete composites: An experimental study. Constr. Build. Mater. 2016, 120, 382-392. [CrossRef]

14. Shariati, A.; Shariati, M.; Sulong, N.H.R.; Suhatril, M.; Khanouki, M.A.; Mahoutian, M. Experimental assessment of angle shear connectors under monotonic and fully reversed cyclic loading in high strength concrete. Constr. Build. Mater. 2014, 52, 276-283. [CrossRef]

15. Mohammadhassani, M.; Akib, S.; Shariati, M.; Suhatril, M.; Khanouki, M.A. An experimental study on the failure modes of high strength concrete beams with particular references to variation of the tensile reinforcement ratio. Eng. Fail. Anal. 2014, 41, 73-80. [CrossRef]

16. Sun, J.; Huang, Y.; Aslani, F.; Wang, X.; Ma, G. Mechanical enhancement for EMW-absorbing cementitious material using 3D concrete printing. J. Build. Eng. 2021, 41, 102763. [CrossRef]

17. Sun, J.; Aslani, F.; Wei, J.; Wang, X. Electromagnetic absorption of copper fiber oriented composite using 3D printing. Constr. Build. Mater. 2021, 300, 124026. [CrossRef]

18. Singh, V.; Gu, N.; Wang, X. A theoretical framework of a BIM-based multi-disciplinary collaboration platform. Autom. Constr. 2011, 20, 134-144. [CrossRef]

19. Sun, J.; Aslani, F.; Lu, J.; Wang, L.; Huang, Y.; Ma, G. Fresh and mechanical behaviour of developed fibre-reinforced lightweight engineered cementitious composites for 3D concrete printing containing hollow glass microspheres. Ceram. Int. 2021, 47, 27107-27121. [CrossRef]

20. Liu, J.; Wu, C.; Wu, G.; Wang, X. A novel differential search algorithm and applications for structure design. Appl. Math. Comput. 2015, 268, 246-269. [CrossRef]

21. Sun, J.; Huang, Y.; Aslani, F.; Ma, G. Properties of a double-layer EMW-absorbing structure containing a graded nano-sized absorbent combing extruded and sprayed 3D printing. Constr. Build. Mater. 2020, 261, 120031. [CrossRef]

22. Sun, J.; Huang, Y.; Aslani, F.; Ma, G. Electromagnetic wave absorbing performance of 3D printed wave-shape copper solid cementitious element. Cem. Concr. Compos. 2020, 114, 103789. [CrossRef] 
23. Ma, G.; Sun, J.; Aslani, F.; Huang, Y.; Jiao, F. Review on electromagnetic wave absorbing capacity improvement of cementitious material. Constr. Build. Mater. 2020, 262, 120907. [CrossRef]

24. Sun, J.; Wang, Y.; Liu, S.; Dehghani, A.; Xiang, X.; Wei, J.; Wang, X. Mechanical, chemical and hydrothermal activation for waste glass reinforced cement. Constr. Build. Mater. 2021, 301, 124361. [CrossRef]

25. Li, J.; Qin, Q.; Sun, J.; Ma, Y.; Li, Q. Mechanical and conductive performance of electrically conductive cementitious composite using graphite, steel slag, and GGBS. Struct. Concr. 2020. [CrossRef]

26. Aslani, F.; Dehghani, A.; Wang, L. The effect of hollow glass microspheres, carbon nanofibers and activated carbon powder on mechanical and dry shrinkage performance of ultra-lightweight engineered cementitious composites. Constr. Build. Mater. 2021, 280, 122415. [CrossRef]

27. Dehghani, A.; Aslani, F.; Panah, N.G. Effects of initial $\mathrm{SiO}_{2} / \mathrm{Al}_{2} \mathrm{O}_{3}$ molar ratio and slag on fly ash-based ambient cured geopolymer properties. Constr. Build. Mater. 2021, 293, 123527. [CrossRef]

28. Aslani, F.; Deghani, A.; Asif, Z. Development of lightweight rubberized geopolymer concrete by using polystyrene and recycled crumb-rubber aggregates. J. Mater. Civ. Eng. 2020, 32, 04019345. [CrossRef]

29. Aslani, F.; Sun, J.; Huang, G. Mechanical behavior of fiber-reinforced self-compacting rubberized concrete exposed to elevated temperatures. J. Mater. Civ. Eng. 2019, 31, 04019302. [CrossRef]

30. Aslani, F.; Sun, J.; Bromley, D.; Ma, G. Fiber-reinforced lightweight self-compacting concrete incorporating scoria aggregates at elevated temperatures. Struct. Concr. 2019, 20, 1022-1035. [CrossRef]

31. Aslani, F.; Hou, L.; Nejadi, S.; Sun, J.; Abbasi, S. Experimental analysis of fiber-reinforced recycled aggregate self-compacting concrete using waste recycled concrete aggregates, polypropylene, and steel fibers. Struct. Concr. 2019, 20, 1670-1683. [CrossRef]

32. Sun, J.; Lin, S.; Zhang, G.; Sun, Y.; Zhang, J.; Chen, C.; Morsy, A.M.; Wang, X. The effect of graphite and slag on electrical and mechanical properties of electrically conductive cementitious composites. Constr. Build. Mater. 2021, 281, 122606. [CrossRef]

33. Feng, J.; Chen, B.; Sun, W.; Wang, Y. Microbial induced calcium carbonate precipitation study using Bacillus subtilis with application to self-healing concrete preparation and characterization. Constr. Build. Mater. 2021, 280, 122460. [CrossRef]

34. Aslani, F.; Gunawardena, Y.; Dehghani, A. Behaviour of concrete filled glass fibre-reinforced polymer tubes under static and flexural fatigue loading. Constr. Build. Mater. 2019, 212, 57-76. [CrossRef]

35. Sun, J.; Ma, Y.; Li, J.; Zhang, J.; Ren, Z.; Wang, X. Machine learning-aided design and prediction of cementitious composites containing graphite and slag powder. J. Build. Eng. 2021, 43, 102544. [CrossRef]

36. Sun, J.; Wang, Y.; Yao, X.; Ren, Z.; Zhang, G.; Zhang, C.; Chen, X.; Ma, W.; Wang, X. Machine-Learning-Aided Prediction of Flexural Strength and ASR Expansion for Waste Glass Cementitious Composite. Appl. Sci. 2021, 11, 6686. [CrossRef]

37. Zhang, J.; Sun, Y.; Li, G.; Wang, Y.; Sun, J.; Li, J. Machine-learning-assisted shear strength prediction of reinforced concrete beams with and without stirrups. Eng. Comput. 2020, 36, 1-15. [CrossRef]

38. Wu, C.; Wang, X.; Chen, M.; Kim, M.J. Differential received signal strength based RFID positioning for construction equipment tracking. Adv. Eng. Inform. 2019, 42, 100960. [CrossRef]

39. Wang, L.; Yuan, J.; Wu, C.; Wang, X. Practical algorithm for stochastic optimal control problem about microbial fermentation in batch culture. Optim. Lett. 2019, 13, 527-541. [CrossRef]

40. Sun, Y.; Zhang, J.; Li, G.; Wang, Y.; Sun, J.; Jiang, C. Optimized neural network using beetle antennae search for predicting the unconfined compressive strength of jet grouting coalcretes. Int. J. Numer. Anal. Methods Geomech. 2019, 43, 801-813. [CrossRef]

41. Sun, Y.; Zhang, J.; Li, G.; Ma, G.; Huang, Y.; Sun, J.; Nener, B. Determination of Young's modulus of jet grouted coalcretes using an intelligent model. Eng. Geol. 2019, 252, 43-53. [CrossRef]

42. Feng, W.; Wang, Y.; Sun, J.; Tang, Y.; Wu, D.; Jiang, Z.; Wang, J.; Wang, X. Prediction of thermo-mechanical properties of rubber-modified recycled aggregate concrete. Constr. Build. Mater. 2022, 318, 125970. [CrossRef]

43. Sun, Y.; Li, G.; Zhang, J.; Sun, J.; Huang, J.; Taherdangkoo, R. New Insights of Grouting in Coal Mass: From Small-Scale Experiments to Microstructures. Sustainability 2021, 13, 9315. [CrossRef]

44. Huynh, A.T.; Nguyen, Q.D.; Xuan, Q.L.; Magee, B.; Chung, T.; Tran, K.T.; Nguyen, K.T. A machine learning-assisted numerical predictor for compressive strength of geopolymer concrete based on experimental data and sensitivity analysis. Appl. Sci. 2020, 10, 7726. [CrossRef]

45. Lieu, Q.X.; Nguyen, K.T.; Dang, K.D.; Lee, S.; Kang, J.; Lee, J. An adaptive surrogate model to structural reliability analysis using deep neural network. Expert Syst. Appl. 2022, 189, 116104. [CrossRef]

46. Lee, S.; Park, S.; Kim, T.; Lieu, Q.X.; Lee, J. Damage quantification in truss structures by limited sensor-based surrogate model. Appl. Acoust. 2021, 172, 107547. [CrossRef]

47. Shariati, M.; Armaghani, D.J.; Khandelwal, M.; Zhou, J.; Khorami, M. Assessment of longstanding effects of fly ash and silica fume on the compressive strength of concrete using extreme learning machine and artificial neural network. J. Adv. Eng. Comput. 2021, 5, 50-74. [CrossRef]

48. Shariati, M.; Trung, N.T.; Wakil, K.; Mehrabi, P.; Safa, M.; Khorami, M. Estimation of moment and rotation of steel rack connections using extreme learning machine. Steel Compos. Struct. 2019, 31, 427-435.

49. Trung, N.T.; Shahgoli, A.F.; Zandi, Y.; Shariati, M.; Wakil, K.; Safa, M.; Khorami, M. Moment-rotation prediction of precast beam-to-column connections using extreme learning machine. Struct. Eng. Mech. 2019, 70, 639-647. 
50. Mohammadhassani, M.; Nezamabadi-Pour, H.; Suhatril, M.; Shariati, M. An evolutionary fuzzy modelling approach and comparison of different methods for shear strength prediction of high-strength concrete beams without stirrups. Smart Struct. Syst. Int. J. 2014, 14, 785-809. [CrossRef]

51. Sun, J.; Wang, X.; Zhang, J.; Xiao, F.; Sun, Y.; Ren, Z.; Zhang, G.; Liu, S.; Wang, Y. Multi-objective optimisation of a graphite-slag conductive composite applying a BAS-SVR based model. J. Build. Eng. 2021, 44, 103223. [CrossRef]

52. Sun, Y.; Li, G.; Zhang, J.; Sun, J.; Xu, J. Development of an ensemble intelligent model for assessing the strength of cemented paste backfill. Adv. Civ. Eng. 2020, 2020, 1643529. [CrossRef]

53. Zhang, C.; Ali, A. The advancement of seismic isolation and energy dissipation mechanisms based on friction. Soil Dyn. Earthq. Eng. 2021, 146, 106746. [CrossRef]

54. Chandwani, V.; Agrawal, V.; Nagar, R. Modeling slump of ready mix concrete using genetic algorithms assisted training of Artificial Neural Networks. Expert Syst. Appl. 2015, 42, 885-893. [CrossRef]

55. Tang, Y.; Feng, W.; Chen, Z.; Nong, Y.; Guan, S.; Sun, J. Fracture behavior of a sustainable material: Recycled concrete with waste crumb rubber subjected to elevated temperatures. J. Clean. Prod. 2021, 318, 128553. [CrossRef]

56. Zhao, R.; Zhang, L.; Guo, B.; Chen, Y.; Fan, G.; Jin, Z.; Guan, X.; Zhu, J. Unveiling substitution preference of chromium ions in sulphoaluminate cement clinker phases. Compos. Part B Eng. 2021, 222, 109092. [CrossRef]

57. Shariati, M.; Mafipour, M.S.; Mehrabi, P.; Ahmadi, M.; Wakil, K.; Trung, N.T.; Toghroli, A. Prediction of concrete strength in presence of furnace slag and fly ash using Hybrid ANN-GA (Artificial Neural Network-Genetic Algorithm). Smart Struct. Syst. 2020, 25, 183-195.

58. Shariati, M.; Mafipour, M.S.; Mehrabi, P.; Bahadori, A.; Zandi, Y.; Salih, M.N.A.; Nguyen, H.; Dou, J.; Song, X.; Poi-Ngian, S. Application of a hybrid artificial neural network-particle swarm optimization (ANN-PSO) model in behavior prediction of channel shear connectors embedded in normal and high-strength concrete. Appl. Sci. 2019, 9, 5534. [CrossRef]

59. Sharafati, A.; Haghbin, M.; Aldlemy, M.S.; Mussa, M.H.; Al Zand, A.W.; Ali, M.; Bhagat, S.K.; Al-Ansari, N.; Yaseen, Z.M. Development of advanced computer aid model for shear strength of concrete slender beam prediction. Appl. Sci. 2020, $10,3811$. [CrossRef]

60. Sharafati, A.; Naderpour, H.; Salih, S.Q.; Onyari, E.; Yaseen, Z.M. Simulation of foamed concrete compressive strength prediction using adaptive neuro-fuzzy inference system optimized by nature-inspired algorithms. Front. Struct. Civ. Eng. 2021, 15, 61-79. [CrossRef]

61. Zhang, G.; Ali, Z.H.; Aldlemy, M.S.; Mussa, M.H.; Salih, S.Q.; Hameed, M.M.; Al-Khafaji, Z.S.; Yaseen, Z.M. Reinforced concrete deep beam shear strength capacity modelling using an integrative bio-inspired algorithm with an artificial intelligence model. Eng. Comput. 2020, 36, 1-14. [CrossRef]

62. Ashrafian, A.; Shokri, F.; Amiri, M.J.T.; Yaseen, Z.M.; Rezaie-Balf, M. Compressive strength of Foamed Cellular Lightweight Concrete simulation: New development of hybrid artificial intelligence model. Constr. Build. Mater. 2020, 230, 117048. [CrossRef]

63. Shariati, M.; Mafipour, M.S.; Ghahremani, B.; Azarhomayun, F.; Ahmadi, M.; Trung, N.T.; Shariati, A. A novel hybrid extreme learning machine-grey wolf optimizer (ELM-GWO) model to predict compressive strength of concrete with partial replacements for cement. Eng. Comput. 2020, 36, 1-23. [CrossRef]

64. Shariati, M.; Mafipour, M.S.; Mehrabi, P.; Zandi, Y.; Dehghani, D.; Bahadori, A.; Shariati, A.; Trung, N.T.; Poi-Ngian, S. Application of Extreme Learning Machine (ELM) and Genetic Programming (GP) to design steel-concrete composite floor systems at elevated temperatures. Steel Compos. Struct. 2019, 33, 319-332.

65. Chahnasir, E.S.; Zandi, Y.; Shariati, M.; Dehghani, E.; Toghroli, A.; Mohamad, E.T.; Shariati, A.; Safa, M.; Wakil, K.; Khorami, M. Application of support vector machine with firefly algorithm for investigation of the factors affecting the shear strength of angle shear connectors. Smart Struct. Syst. 2018, 22, 413-424.

66. Luo, Y.; Zheng, H.; Zhang, H.; Liu, Y. Fatigue reliability evaluation of aging prestressed concrete bridge accounting for stochastic traffic loading and resistance degradation. Adv. Struct. Eng. 2021, 24, 3021-3029. [CrossRef]

67. Mou, B.; Bai, Y. Experimental investigation on shear behavior of steel beam-to-CFST column connections with irregular panel zone. Eng. Struct. 2018, 168, 487-504. [CrossRef]

68. Lieu, Q.X.; Do, D.T.; Lee, J. An adaptive hybrid evolutionary firefly algorithm for shape and size optimization of truss structures with frequency constraints. Comput. Struct. 2018, 195, 99-112. [CrossRef]

69. Nguyen-Van, S.; Nguyen, K.T.; Luong, V.H.; Lee, S.; Lieu, Q.X. A novel hybrid differential evolution and symbiotic organisms search algorithm for size and shape optimization of truss structures under multiple frequency constraints. Expert Syst. Appl. 2021, 184, 115534. [CrossRef]

70. Nguyen-Van, S.; Nguyen, K.T.; Dang, K.D.; Nguyen, N.T.; Lee, S.; Lieu, Q.X. An evolutionary symbiotic organisms search for multiconstraint truss optimization under free vibration and transient behavior. Adv. Eng. Softw. 2021, 160, 103045. [CrossRef]

71. Al-Shamiri, A.K.; Kim, J.H.; Yuan, T.-F.; Yoon, Y.S. Modeling the compressive strength of high-strength concrete: An extreme learning approach. Constr. Build. Mater. 2019, 208, 204-219. [CrossRef]

72. Farrar, D.E.; Glauber, R.R. Multicollinearity in regression analysis: The problem revisited. Rev. Econ. Stat. 1967, 49, 92-107. [CrossRef]

73. Lu, N.; Wang, H.; Wang, K.; Liu, Y. Maximum Probabilistic and Dynamic Traffic Load Effects on Short-to-Medium Span Bridges. Comput. Model. Eng. Sci. 2021, 127, 345-360. [CrossRef] 
74. Xu, J.; Lan, W.; Ren, C.; Zhou, X.; Wang, S.; Yuan, J. Modeling of coupled transfer of water, heat and solute in saline loess considering sodium sulfate crystallization. Cold Reg. Sci. Technol. 2021, 189, 103335. [CrossRef]

75. Zhang, J.; Huang, Y.; Wang, Y.; Ma, G. Multi-objective optimization of concrete mixture proportions using machine learning and metaheuristic algorithms. Constr. Build. Mater. 2020, 253, 119208. [CrossRef]

76. Ni, T.; Liu, D.; Xu, Q.; Huang, Z.; Liang, H.; Yan, A. Architecture of cobweb-based redundant TSV for clustered faults. IEEE Trans. Very Large Scale Integr. (VLSI) Syst. 2020, 28, 1736-1739. [CrossRef]

77. Wang, J.; Chen, H. BSAS: Beetle swarm antennae search algorithm for optimization problems. arXiv 2018, arXiv:1807.10470.

78. Zhang, J.; Huang, Y.; Ma, G.; Nener, B. Mixture optimization for environmental, economical and mechanical objectives in silica fume concrete: A novel frame-work based on machine learning and a new meta-heuristic algorithm. Resour. Conserv. Recycl. 2021, 167, 105395. [CrossRef]

79. Cortez, P.; Embrechts, M.J. Using sensitivity analysis and visualization techniques to open black box data mining models. Inf. Sci. 2013, 225, 1-17. [CrossRef]

80. Zhang, J.; Wang, Y. Evaluating the bond strength of FRP-to-concrete composite joints using metaheuristic-optimized least-squares support vector regression. Neural Comput. Appl. 2021, 33, 3621-3635. [CrossRef]

81. Shariati, M.; Mafipour, M.S.; Haido, J.H.; Yousif, S.T.; Toghroli, A.; Trung, N.T.; Shariati, A. Identification of the most influencing parameters on the properties of corroded concrete beams using an Adaptive Neuro-Fuzzy Inference System (ANFIS). Steel Compos. Struct. 2020, 34, 155.

82. Safa, M.; Shariati, M.; Ibrahim, Z.; Toghroli, A.; Baharom, S.B.; Nor, N.M.; Petkovic, D. Potential of adaptive neuro fuzzy inference system for evaluating the factors affecting steel-concrete composite beam's shear strength. Steel Compos. Struct. 2016, 21, 679-688. [CrossRef] 